Guideline

\title{
Care and Management of Voice Change in Thyroid Surgery: Korean Society of Laryngology, Phoniatrics and Logopedics Clinical Practice Guideline
}

\begin{abstract}
Korean Society of Laryngology, Phoniatrics and Logopedics Guideline Task Force; Chang Hwan Ryu ${ }^{1, *}$ (D)

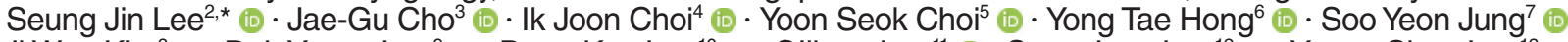

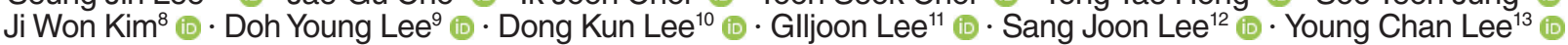
Yong Sang Lee ${ }^{14}$ (D) $\cdot$ Inn Chul Nam ${ }^{15}$ (D) $\cdot$ Ki Nam Park $^{16}$ (iD $\cdot$ Young Min Park $^{17}$ (D) $\cdot$ Eui-Suk Sung ${ }^{18}$ (iD $\cdot$ Hee Young Son $^{19}$ (i) In Hyo Seo ${ }^{20}$ (i) $\cdot$ Byung-Joo Lee ${ }^{18,21}$ (iD $\cdot$ Jae-Yol Lim ${ }^{17}$ (iD

${ }^{l}$ Department of Otorhinolaryngology-Head and Neck Surgery, National Cancer Center, Goyang; ${ }^{2}$ Division of Speech Pathology and Audiology, Research Institute of Audiology and Speech Pathology, College of Natural Sciences, Hallym University, Chuncheon; ${ }^{3}$ Department of Otorhinolaryngology-Head and Neck Surgery, Korea University College of Medicine, Seoul; ${ }^{4}$ Department of Otorhinolaryngology-Head and Neck Surgery, Korea Cancer Center Hospital, Korea Institute of Radiological and Medical Sciences, Seoul; ${ }^{5}$ Department of Otorhinolaryngology-Head and Neck Surgery, Yeungnam University College of Medicine, Daegu; ${ }^{6}$ Department of Otorhinolaryngology-Head and Neck Surgery, Jeonbuk National University Hospital, Jeonbuk National University Medical School, Jeonju; ${ }^{7}$ Department of Otorhinolaryngology-Head and Neck Surgery, Ewha Womans University College of Medicine, Seoul; ${ }^{8}$ Department of Otorhinolaryngology-Head and Neck Surgery, Inha University College of Medicine, Incheon; ${ }^{9}$ Department of Otorhinolaryngology-Head and Neck Surgery, Seoul National University Boramae Medical Center, Seoul National University College of Medicine, Seoul, ${ }^{10}$ Department of Otorhinolaryngology-Head and

Neck Surgery, Dong-A University College of Medicine, Busan; ${ }^{11}$ Department of Otorhinolaryngology-Head and Neck Surgery, Kyungpook National University, School of Medicine, Daegu; ${ }^{12}$ Department of Otorhinolaryngology-Head and Neck Surgery, Dankook University College of Medicine, Cheonan; ${ }^{13}$ Department of Otorhinolaryngology-Head and Neck Surgery, Kyung Hee University School of Medicine, Seoul; ${ }^{14}$ Department of Surgery, Yonsei University College of Medicine, Seoul; ${ }^{15}$ Department of Otorhinolaryngology-Head and Neck Surgery, College of Medicine, The Catholic University of Korea, Seoul; ${ }^{16}$ Department of Otorhinolaryngology-Head and Neck Surgery, Soonchunhyang University College of Medicine, Bucheon; ${ }^{17}$ Department of Otorhinolaryngology-Head and Neck Surgery, Yonsei University College of Medicine, Seoul; ${ }^{18}$ Department of Otorhinolaryngology-Head and Neck Surgery, Pusan National University School of Medicine: ${ }^{19}$ Department of Otorhinolaryngology-Head and Neck Surgery, Dongnam Institute Of Radiological and Medical Sciences, Busan; ${ }^{20}$ Voice and Speech Clinic, Department of Otorhinolaryngology-Head and Neck Surgery, Dankook University College of Medicine, Cheonan; ${ }^{21}$ Biomedical Research Institute, Pusan National University Hospital, Busan, Korea
\end{abstract}

\begin{abstract}
Voice change is a common complaint after thyroid surgery and has a significant impact on quality of life. The Korean Society of Laryngology, Phoniatrics and Logopedics assembled a task force to establish guideline recommendations on education, care, and management related to thyroid surgery. The guideline recommendations encompass preoperative voice education, management of anticipated voice change during surgery, and comprehensive voice care after thyroid surgery, and include in-depth information and up-to-date knowledge based on validated literature. The committee constructed 14 key questions (KQs) in three categories-preoperative (KQ 1-2), intraoperative (KQ 3-8), and postoperative (KQ 9-14) management - and developed 18 evidence-based recommendations. The Delphi survey reached an agreement on each recommendation. A detailed evidence profile is presented for each recommendation. The level of evidence for each recommendation was classified as high-quality, moderate-quality, or low-quality. The strength of each recommendation was designated as strong or weak considering the level of evidence supporting the recommendation. The guidelines are primarily targeted toward physicians who treat thyroid surgery patients and speech-language pathologists participating in patient care. These guidelines will also help primary care physicians, nurses, healthcare policymakers, and patients improve their understanding of voice changes and voice care after thyroid surgery.
\end{abstract}

Keywords. Thyroidectomy; Guideline; Voice; Dysphonia; Thyroid Neoplasms

- Received March 30, 2021

Revised May 25, 2021

Accepted May 31, 2021

- Corresponding author: Jae-Yol Lim

Department of Otorhinolaryngology, Gangnam Severance Hospital, Yonsei

University College of Medicine, 211 Eonju-ro, Gangnam-gu, Seoul 06273,

Korea

Tel: +82 2-2019-3460, Fax: +82 2-3463-4750

E-mail: jylimmd@yuhs.ac

\footnotetext{
- Co-Corresponding author: Byung-Joo Lee

Department of Otorhinolaryngology-Head and Neck Surgery, Pusan

National University School of Medicine, and Biomedical Research Institute, Pusan National University Hospital, 179 Gudeok-ro, Seo-gu, Busan 49241, Korea

Tel: +82-51-240-7675; Fax: +82-51-246-8668

E-mail: voiceleebj@gmail.com

*These authors contributed equally to this work as first authors.
}

Copyright $($ C) 2022 by Korean Society of Otorhinolaryngology-Head and Neck Surgery.

This is an open-access article distributed under the terms of the Creative Commons Attribution Non-Commercial License (https://creativecommons.org/licenses/by-nc/4.0) which permits unrestricted non-commercial use, distribution, and reproduction in any medium, provided the original work is properly cited. 


\section{INTRODUCTION}

Thyroid surgery is most often performed to treat thyroid cancer. Until 2014, thyroid cancer was the most common cancer in the Republic of Korea, ranking first in incidence among all cancers and ranking third among all malignant tumors in 2016. It is the second most common cancer in women and the most common cancer for both sexes in the 15-34 age group [1].

The extent of thyroidectomy remains debated due to potential complications, such as hypoparathyroidism and recurrent laryngeal nerve (RLN) injury, impairing quality of life (QOL), although total thyroidectomy (TT) has long been considered as the standard treatment for thyroid cancer. TT controls thyroid cancer with multiple tumor foci and facilitates the interpretation of serum thyroglobulin for predicting recurrence during the postoperative period. Radioactive iodine may be added after TT to ablate remnant thyroid tissues and potential residual lesions. Nevertheless, the American Thyroid Association (ATA) and Korean Thyroid Association (KTA) recommend a more conservative thyroid surgery approach, suggesting that thyroid lobectomy may be enough for differentiated thyroid cancer smaller than $4 \mathrm{~cm}$ without extrathyroidal extension $[2,3]$.

Voice change is a common problem that patients encounter after thyroid surgery. Approximately $30 \%$ to $80 \%$ of patients complain of voice alteration after thyroid surgery [4-12]. Although the pathogenesis of voice change related to thyroid surgery remains elusive, RLN injuries have been definitively established as a cause, with post-surgical rates ranging from $2.3 \%$ to $26 \%$ [13]. Patients with RLN injuries do not always present with voice change; thus, clinicians sometimes do not recognize patients' RLN status during the postoperative follow-up. Injury to the external branch of the superior laryngeal nerve (EBSLN) is another well-known cause of voice change. EBSLN injury results in difficulty in speaking in a high tone or singing $[14,15]$. Furthermore, some patients demonstrate voice change after thyroid surgery without obvious nerve injuries. Several pathophysiologic mechanisms related to voice change other than RLN or EBSLN injury have been proposed, including wound fibrosis, laryngotracheal fixation, venous congestion due to vascular ligation during surgery, edema of the vocal folds by interruption of lymphatic flow around the larynx, and laryngeal compression by balloon intubation during general anesthesia.

\section{H I G H L I G H H T S}

- This guideline provides recommendations on voice management related to thyroid surgery.

- Fourteen key questions related to preoperative, intraoperative, and postoperative management were identified.

- Based on these key questions, 18 evidence-based recommendations were developed.
Speech is a tool for sharing thoughts with others, communicating ideas, and achieving social activity; thus, voice alterations have a profound impact on QOL [6]. In 2013, the American Academy of Otolaryngology-Head and Neck Surgery released clinical practice guidelines (CPGs) for voice care following thyroid surgery [6]. In the 2015 ATA and 2016 KTA guidelines for thyroid nodules, laryngeal examinations were recommended before thyroid surgery $[2,3]$. The Korean Society of Laryngology, Phoniatrics and Logopedics (KSLPL) recognized the necessity of voice care given current trends and sought to develop a new standard CPG for voice management related to thyroid surgery.

\section{INTENDED USERS}

The guidelines are intended for all clinicians treating thyroid surgery and speech-language pathologists (SLPs) participating in patient care. These guidelines also aim to promote an improved understanding of voice change after thyroid surgery among policymakers, counselors, and patients scheduled to undergo thyroid surgery.

\section{ORGANIZATION OFTHE COMMITTEE AND SELECTION OF KEY QUESTIONS}

The committee was organized into advisory, operating, and working groups. The operating members included the committee chair and two executives appointed by the KSLPL. The advisory group consisted of 19 KSLPL board members with extensive clinical experience. The working group consisted of 19 KSLPL members. The advisory and operating groups identified the subject requiring CPG development as "voice care for patients undergoing thyroid surgery" and then confirmed the 14 key questions (KQ; consisting of two preoperative, six intraoperative, and six postoperative questions) (Table 1) during the first three meetings. The working group participated in the development of the CPG independently of the KSLPL. The committee held a kick-off meeting on April 28, 2019, and participated in monthly conference calls to develop the CPG.

\section{LITERATURE SEARCH}

A literature search of the OVID Medline, Embase, Cochrane Library, and KoreaMED databases was conducted on July 25, 2019, using search words selected by the committee. The retrieved articles were collected in Endnote X9 (Thomson Reuters, New York, NY, USA). After automatically removing duplicates, the committee members selected potentially relevant papers according to the title/abstract. The inclusion criteria were as follows: (1) 
Table 1. Organization of the KSLPL guidelines of voice care and management in the treatment of voice change after thyroid surgery

Location key
[A] Preoperative management
[Key question 1] Is preoperative laryngeal visual examination necessary?
[Key question 2] Is preoperative voice assessment necessary?
[B] Intraoperative management
[Key question 3] Is perioperative counseling about the impact of surgery on voice and vocal hygiene necessary for thyroid surgery patients?
[Key question 4] Does perioperative systemic corticosteroid administration benefit voice quality after thyroid surgery?
[Key question 5] What are the surgical techniques to preserve the external branch of the superior laryngeal nerve for voice preservation during
thyroidectomy?
[Key question 6] What are the surgical techniques to preserve the recurrent laryngeal nerve for voice preservation during thyroidectomy?
[Key question 7] Is intraoperative neuromonitoring necessary to preserve voice quality during thyroid surgery?
[Key question 8] Does intraoperative recurrent laryngeal nerve reinnervation improve the postoperative voice quality?
[Key question 9] Is postoperative laryngeal visual examination necessary?
$[$ Key question 10] Is comprehensive voice assessment necessary after thyroid surgery?
[Key question 11] Are vocal fold medialization procedures necessary for patients with unilateral vocal fold paralysis after thyroid surgery?
[Key question 12] Is surgical treatment necessary for patients with bilateral VFP after thyroid surgery?
[Key question 13] Is postoperative neck exercise needed to improve neck discomfort in patients with thyroid surgery?

KSLPL, Korean Society of Laryngology, Phoniatrics and Logopedics; VFP, vocal fold paralysis.

human studies, (2) article publication type, and (3) English-language text. The committee members then conducted a full-text review to determine the final relevant papers. The search strategy, number of included/excluded articles, and search are presented in Fig. 1, Supplementary Material 1, and Supplementary Tables 1 and 2.

\section{QUALITY ASSESSMENT OFTHE LITERATURE AND GRADES OF RECOMMENDATIONS AND EVIDENCE LEVELS}

We classified the literature as (1) randomized controlled trials (RCTs) or well-conducted systematic reviews or meta-analyses, (2) prospective cohort studies without randomization, (3) casecontrol studies with participants from multiple centers, (4) retrospective studies, and (5) expert opinions or case series. For quality assessment of studies, the Cochrane Risk of Bias for RCTs, the Risk of Bias AssessmentTool for Nonrandomized Studies v1.5 for non-critical control studies (non-RCTs and observational studies), and A MeasurementTool to Assess the Methodological Quality of Systematic Reviews for systematic reviews or meta-analysis were used $[16,17]$. After completing the guideline statements, we determined the evidence level for each statement based on the articles used to develop the guidelines. The evidence level was classified as high-quality, moderate-quality, or low-quality (Table 2) [16]. The strength of each guideline recommendation was established by the committee after an in-depth discussion considering the evidence level, disease burden, risk/benefit of statements, and local medical circumstances. We adopted the
American College of Physicians grading system (Table 3).The final decision about guideline strength was made at the seventh meeting (September 28, 2019).

\section{CONSENSUS REGARDINGTHE RECOMMENDATIONS AND MANUSCRIPT DEVELOPMENT}

Consensus on the recommendations for each KQ was reached through a Delphi survey. For the Delphi consensus, we sent e-mails to doctors specializing in thyroid surgery for more than 10 years in the KSLPL and executive director members of the KTA, Korean Association of Thyroid and Endocrine Surgeons, Korean Intraoperative Neural Monitoring Society, and Korean Academy of Speech-Language Pathology and Audiology. A total of 73 experts responded to the survey. The respondents were asked to choose one of the following responses: fully agree, agree, neither agree nor disagree, disagree, or fully disagree. A final agreement was reached for each survey item if more than twothirds of the panel members responded with "fully agree" or "agree."

\section{PLAN FOR RELEASE AND UPDATE OF GUIDELINES}

The guideline will be updated every 5 years to reflect new clinical data and the latest trends. 

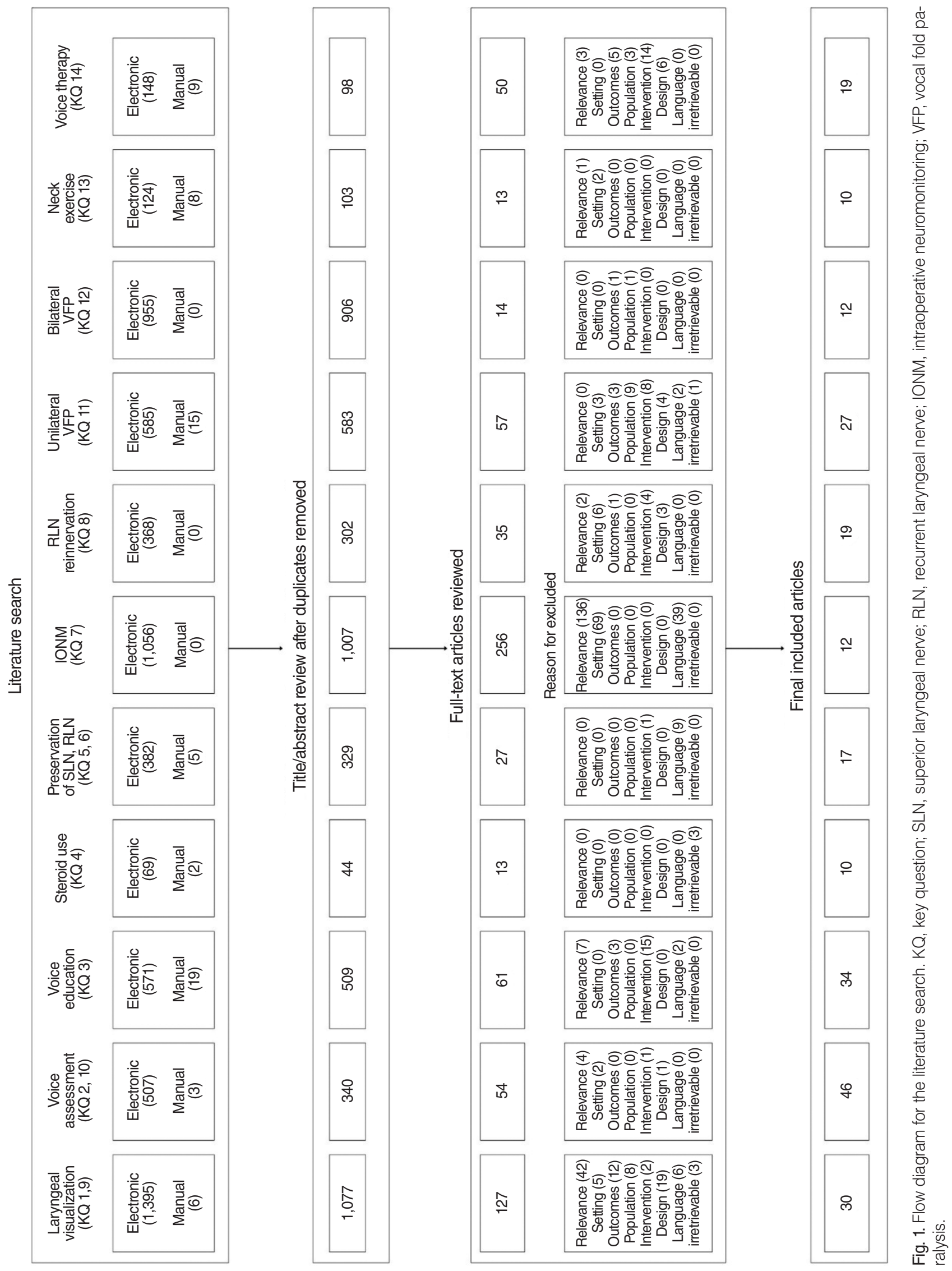
Table 2. Level of evidence

\begin{tabular}{ll}
\hline Term & \multicolumn{1}{c}{ Definition } \\
\hline High-quality of evidence & RCT without important limitations or overwhelming evidence from observational study \\
Moderate-quality of evidence & RCT with important limitations or strong evidence from observational studies \\
Low-quality of evidence & Observational studies/case studies \\
\hline
\end{tabular}

$\mathrm{RCT}$, randomized controlled trial.

Table 3. Interpretation of American College of Physicians grading system

\begin{tabular}{|c|c|c|c|}
\hline Grade of recommendation & Benefit vs. risks and burdens & Interpretation & Implication \\
\hline \multicolumn{4}{|l|}{ Strong recommendation } \\
\hline $\begin{array}{l}\text { High-quality of evidence } \\
\text { Moderate-quality of evidence } \\
\text { Low-quality of evidence }\end{array}$ & $\begin{array}{l}\text { Benefits clearly outweigh risks } \\
\text { and burden or vice versa. }\end{array}$ & $\begin{array}{l}\text { Strong recommendation—can apply to } \\
\text { most patients in most circumstances } \\
\text { without reservation. } \\
\text { Strong recommendation—-but may } \\
\text { change when higher-quality evidence } \\
\text { becomes available. }\end{array}$ & $\begin{array}{l}\text { For patients: most would want the } \\
\text { recommended course and only a small } \\
\text { proportion would not. } \\
\text { For clinicians: most patients should receive } \\
\text { the recommended course of action. }\end{array}$ \\
\hline \multicolumn{4}{|l|}{ Weak recommendation } \\
\hline $\begin{array}{l}\text { High-quality of evidence } \\
\text { Moderate-quality of evidence } \\
\text { Low-quality of evidence }\end{array}$ & $\begin{array}{l}\text { Benefits closely balanced with } \\
\text { risk and burden. } \\
\text { Uncertainty in the estimates of } \\
\text { benefits, risks, and burden; } \\
\text { benefits, risks, and burden } \\
\text { may be closely balanced. }\end{array}$ & $\begin{array}{l}\text { Weak recommendation, best action } \\
\text { may differ depending on } \\
\text { circumstances or patients' or societal } \\
\text { values. } \\
\text { Very weak recommendation, other } \\
\text { alternatives may be reasonable. }\end{array}$ & $\begin{array}{l}\text { For patients: most would want the } \\
\text { recommended course of action, but some } \\
\text { would not. A decision may depend on an } \\
\text { individual's circumstances. } \\
\text { For clinicians: different choices will be } \\
\text { appropriate for different patients, and a } \\
\text { management decision consistent with a } \\
\text { patient's values, preferences, and } \\
\text { circumstances should be reached. }\end{array}$ \\
\hline \multicolumn{4}{|l|}{ No recommendation } \\
\hline Insufficient evidence & $\begin{array}{l}\text { Balance of benefits and risks } \\
\text { cannot be determined. }\end{array}$ & $\begin{array}{l}\text { Insufficient evidence to recommend } \\
\text { for or against routinely providing the } \\
\text { service }\end{array}$ & $\begin{array}{l}\text { For patients: decisions based on evidence } \\
\text { from scientific studies cannot be made. } \\
\text { For clinicians: decisions based on evidence } \\
\text { from scientific studies cannot be made }\end{array}$ \\
\hline
\end{tabular}

\section{A. Preoperative management}

$K Q$ 1. Is preoperative laryngeal visual examination necessary?

Population: patients undergoing thyroid surgery

Intervention: performing a preoperative laryngeal visual examination

Comparison: not performing a preoperative laryngeal visual examination

Outcome: detecting the rate of laryngeal abnormalities

\section{Recommendation}

The clinician should perform preoperative laryngeal visualization in all patients undergoing thyroid surgery (strong recommendation, moderate-quality evidence).

Expert opinion $(\mathrm{n}=57)$ : fully agree $(40,70.2 \%)$, agree $(8$, $14.0 \%)$, neither agree nor disagree $(2,3.5 \%)$, disagree $(7$, $12.3 \%$ ), fully disagree $(0)$

Preoperative laryngeal visualization is recommended because it can (1) assess vocal fold mobility as well as vocal fold mucosal lesions in patients with vocal symptoms, (2) identify normalvoiced patients with pre-existing vocal fold paralysis (VFP), (3) predict the possibility of extrathyroidal extension of thyroid cancers and establish a proper surgical plan, and (4) evaluate the baseline status of preoperative laryngeal function for postoperative voice care.

Farrag et al. [18] reported that $32 \%$ of patients with impaired vocal fold movement before thyroid surgery were asymptomatic. Randolph and Kamani [19] also reported that $67 \%$ of invasive cases presenting with preoperative vocal cord paralysis did not have voice change at presentation. In the cases of median fixation of a paralyzed vocal fold in the absence of a glottal gap, mucosal wave propagation can occur during phonation. The resulting voice sounds normal, and patients may not recognize their voice change. Furthermore, a complaint of voice problems before thyroidectomy does not always indicate VFP. Nam et al. [20] investigated the incidence of coincident abnormal laryngeal lesions for patients who had dysphonia before thyroidectomy and found that approximately $35 \%$ of patients had laryngeal mucosal lesions, including vocal nodule, vocal polyp, Reinke's edema, and vocal cyst, as well as VFP. Pre-existing laryngeal lesions may affect voice quality after thyroidectomy. 
The presence of VFP before thyroid surgery implies the invasive nature of thyroid cancer because gross invasion of the RLN by thyroid cancer is correlated with a high recurrence rate and mortality rate [21]. If cancer involves the RLN, the surgeon must secure a safe resection margin and preserve the contralateral RLN. However, it is often challenging to determine whether the RLN is invaded by thyroid cancer when it is close to the posterior thyroid capsule. A previous study reported that laryngoscopy showed $76 \%$ sensitivity and $100 \%$ specificity for predicting RLN invasion, whereas neck computed tomography (CT) showed 23\% sensitivity [19].

Vocal fold mobility can be assessed using various instruments, including a mirror, flexible or rigid laryngeal endoscopy, stroboscopy, ultrasonography, and electromyography. The approach used is usually dependent on the institutional facilities. Among them, the flexible laryngoscope has several advantages over other laryngeal instruments. It enables laryngeal visualization with less gag reflex and enables the observation of the vocal fold status in the anteriorly displaced arytenoid and during compensatory supraglottic movement [22-25].

Rigid laryngeal endoscopy is commonly conducted to visualize laryngeal diseases. Still, it may be challenging to observe vocal fold lesions using the rigid laryngeal endoscopy when the gag reflex is provoked or there is anterior displacement of the arytenoid cartilage due to VFP. Laryngeal stroboscopy is the gold standard for assessing mucosal wave propagation during phonation. It also enables a detailed evaluation of vibratory patterns, such as the regularity and symmetry of vibrations, and facilitates the diagnosis of incomplete VFP or combined laryngeal mucosal lesions $[26,27]$. However, if two vocal folds cannot produce sufficient contact with vibration, interpretation via stroboscopic images may be limited. Laryngeal ultrasonography is a non-invasive method that is mainly used in facilities not equipped with laryngeal endoscopes; however, its inter-examiner reliability is relatively low, it is less reliable for patients with calcified thyroid cartilage, and it has a learning curve for the operator [27].

Most otolaryngologists use laryngeal endoscopy (rigid or flexible) to assess vocal fold mobility, and endocrine surgeons usually refer to otolaryngologists to evaluate the vocal fold movement of patients with voice change in Korea. The British Thyroid Association recommends a laryngeal status examination for all patients with thyroid cancer or voice change undergoing thyroid surgery [28].The German Association of Endocrine Surgeons and the International Intraoperative Electrophysiologic Neural Monitoring Society announced that preoperative laryngoscopy is imperative to exclude or verify preexisting VFP in all patients undergoing thyroid surgery $[29,30]$. Organizations from the United States recommend preoperative laryngeal examinations in patients at high risk for RLN injury, including preexisting voice alteration, large thyroid nodules, history of neck surgery, posteriorly located thyroid cancer, and extensive cervical lymph node metastases $[2,6,31,32]$.
The economic burden of rising medical expenses is another consideration. One reason why preoperative laryngeal examinations are performed only in selected patients may be attributed to the cost-to-benefit ratio, especially in low-risk thyroid cancer patients without voice change [33]. However, in Korea, because the cost of a laryngeal endoscope is very low and is also covered by national insurance, the economic burden related to laryngeal examinations is relatively low. In addition, preoperative laryngeal examination and documentation can be used for any medicolegal issues related to postoperative voice changes. Considering the importance of voice, the usefulness of preoperative laryngoscopy, and the cost-to-benefit ratio, the committee recommends that a preoperative laryngeal visual examination should be performed for all thyroid surgery patients.

\section{$K Q$ 2. Is a preoperative voice assessment necessary?}

Population: patients undergoing thyroidectomy Intervention: preoperative voice assessment Comparison: no preoperative voice assessment Outcome: usefulness of the assessment

\section{Recommendations}

1. The clinician should check the voice status of all patients undergoing thyroid surgery (strong recommendation, moderate-quality evidence)

Expert opinion ( $\mathrm{n}=73)$ : fully agree $(47,64.4 \%)$, agree $(15,20.5 \%)$, neither agree nor disagree $(7,9.6 \%)$, disagree (3, $4.1 \%)$, fully disagree $(0)$, no answer $(1,1.4 \%)$

2. In the following cases, a preoperative voice assessment is indicated (strong recommendation, moderate quality of evidence)

- Patients with voice problems before surgery

- Patients with abnormal findings on a laryngeal visual examination before surgery

- Patients at high risk of voice change after surgery Expert opinion ( $\mathrm{n}=73)$ : fully agree $(52,71.2 \%)$, agree $(18,24.7 \%)$, neither agree nor disagree $(2,2.7 \%)$, disagree $(1,1.4 \%)$, fully disagree $(0)$

Approximately $33 \%$ of patients scheduled for thyroidectomy demonstrate preoperative voice symptoms $[34,35]$. Voice problems noted before thyroidectomy can be caused not only by RLN invasion, but also by preexisting voice disorders. For instance, impaired thyroid function may lead to swelling of the vocal folds, causing voice change [36,37]. It is crucial to document preoperative voice status as baseline data to counsel patients about their impaired voice or provide appropriate postoperative voice therapy $[7,11,20]$. Voice status can be easily checked by asking the patients or caregivers if their voice 
sounds "normal" or "different."

A Voice Handicap Index (VHI; VAS) can be used to describe patients' voice status in two aspects: the quality of the voice and the degree to which voice symptoms (if any) affect daily life. The patient assigns a score between 0 and 100 points; a score of 0 means normal, while a higher value indicates abnormal findings [38]. Further voice assessments are recommended if there are any voice symptoms before surgery, abnormal laryngeal findings, or a high risk of RLN injury during surgery. Different voice assessment tools are used depending on the hospital and medical environment; oftentimes, special training is required to interpret the parameters of those tools.

There are several ways to evaluate a patient's voice before surgery, including patient self-assessment, psychosomatic assessment by an experienced SLP, and acoustic analysis of a voice recording using computer software. The former two methods are easy, simple, and highly reproducible methods that do not need specialized assessment equipment. First, for the self-assessment method, patients are asked to report whether they have noticed changes in their vocal pitch, loudness, quality, or endurance. Among various self-assessment questionnaires, the VHI developed by Jacobson in 1997 has been widely used. In 2002, the Agency for Healthcare Research and Quality recognized that, among various voice disorder questionnaires, only the VHI met reliability and validity criteria. Its usefulness has been verified through many studies [6,39]. The questionnaire consists of 30 questions, and a higher score implies a more serious voice problem. Rosen et al. [40] simplified the VHI and proposed the VHI10 , a questionnaire consisting of 10 questions, which has demonstrated similar sensitivity and specificity to those of the VHI in detecting voice problems. Other questionnaires have also been developed at various institutions, such as the Voice-Related Quality of Life, Voice Activity \& Participation Profile (VAPP), Vocal Fatigue Index (VFI), and Thyroidectomy-related Voice Questionnaire [20,41-43].

Patients may also undergo an auditory perceptual assessment, wherein evaluators subjectively evaluate the patient's voice. The most representative tests are the Grade, Roughness, Breathiness, Asthenia, and Strain (GRBAS) and Consensus Auditory-Perceptual Evaluation of Voice (CAPE-V). Two or more experts (a doctor or SLP) listen to samples of the patient's voice (/a/ or /i/ or predefined sentence) and assess their voice status. GRBAS evaluates the voice in terms of the overall grade, roughness, breathiness, asthenia, and strain $[44,45]$, while the CAPE-V assesses overall severity, roughness, breathiness, strain, pitch, and loudness [46]. The European Laryngeal Society recommends only measuring GRB when it is difficult to measure all items of GRBAS [38]. However, as thyroidectomized patients frequently demonstrate strained voices after surgery, the committee suggests GRBS $[47,48]$ if possible. If patients are unable to undergo voice assessments in a clinic, they may send a recorded voice sample. In those instances, patients record their voices while reading familiar sen- tences, such as the national anthem or making the /a/ sound in a quiet environment $[44,45,49]$.

\section{B. Intraoperative management}

$\mathrm{KQ} 3$. Is perioperative counseling about the impact of surgery on voice and vocal hygiene necessary for thyroid surgery patients?

Population: patients undergoing thyroid surgery

Intervention: perioperative patient counseling on voice outcomes

Comparison: no perioperative patient counseling on voice outcomes

Outcome: voice outcomes and patients' satisfaction

\section{Recommendation}

1. The clinicians or SLP should counsel all patients undergoing thyroid surgery about the potential voice impact of thyroid surgery (strong recommendation, low-quality evidence).

Expert opinion $(n=73)$ : fully agree $(42,57.5 \%)$, agree $(27,37.0 \%)$, neither agree nor disagree $(2,2.7 \%)$, disagree $(1,1.4 \%)$, strongly disagree $(0)$, no response $(1,1.4 \%)$

2. Clinicians or SLPs should provide education on vocal hygiene to improve voice quality in patients with voice changes after surgery (strong recommendation, low-quality evidence).

Expert opinion ( $\mathrm{n}=73)$ : fully agree $(42,57.5 \%)$, agree $(27,37.0 \%)$, neither agree nor disagree $(2,2.7 \%)$, disagree $(1,1.4 \%)$, strongly disagree $(0)$, no response $(1,1.4 \%)$

Clinicians should educate patients about the potential risks of voice change, voice hygiene, and possible management of postoperative voice change prior to surgery. The cooperation of patients and their family members is vital for the optimal treatment of voice changes after surgery [50-52]. Clinicians should provide sufficient information about the potential impact of thyroid surgery on voice and the importance of early management or interventions after surgery to encourage patients to actively participate in their treatment. This will help improve patients' QOL after surgery by providing timely and appropriate treatments while maintaining the patient-physician relationship when voice changes occur after surgery [53-56].

The following should be included in the patient's education [6,57]: First, if patients already have voice disorders, the voice may be aggravated after thyroid surgery, despite preservation of the RLN. To rule out preexisting voice disorders, a visual inspection of the larynx should be undertaken before thyroid surgery (see KQ1). In such cases, clinicians or SLPs explain that the voice change may be irrelevant to thyroid disease and plan appropriate treatment strategies. Second, clinicians should explain the 


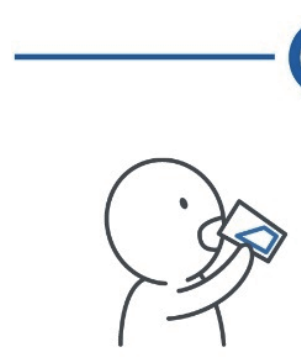

Frequent hydration

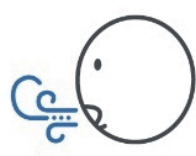

Comfortable breathing
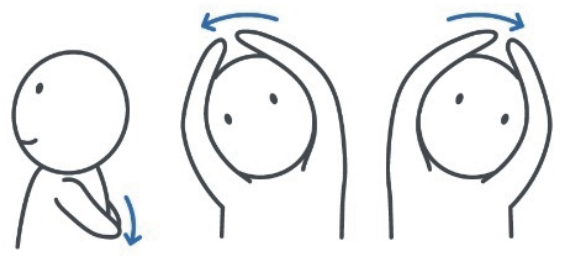

Shoulder stretching

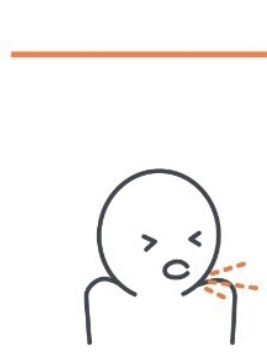

Throat clearing

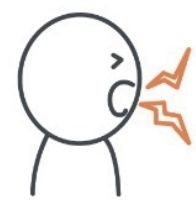

Shouting
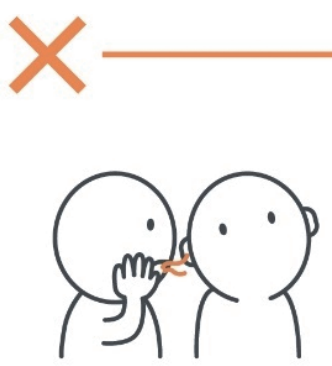

Whispering
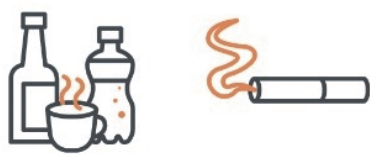

Alcohol

Smoking potential mechanisms of voice change after thyroid surgery, not limited to RLN injury also including general anesthesia and postoperative laryngotracheal structural changes. Clinicians should also include counseling on the timing of intervention, treatment protocols, and follow-up strategies for the management of postoperative voice change. If the patient's voice deteriorates postoperatively, timely management, such as voice therapy and vocal fold medialization, is mandatory [52,58-60].

Several types of patient education information forms can be used. In a randomized study of 125 patients undergoing thyroid surgery, patients who were provide written educational materials, such as pamphlets $(50.3 \%)$, showed higher recall rates for risk factors than those who were not (29.5\%) [59]. However, another randomized study reported no difference in the degree of recall of risk factors after surgery between the two groups [61]. Online educational materials may be too academic or contain outdated information. Recently, information via visual infographics has been highlighted [62,63]. Vocal hygiene education after thyroid surgery helps prevent further voice aggravation and improves the adaptability and satisfaction of surgical interventions for voice alterations. It may also reduce patients' anxiety. A previous study of 251 thyroid surgery patients showed a high demand for education on voice problems after discharge from the hospital [64]. A lack of post-discharge information could lead to poor treatment compliance and unnecessary medical visits.

Vocal hygiene education helps produce a normal voice during phonation, forestalling undesirable postural and lifestyle habits (Fig. 2) [65]. Patients with voice changes due to VFP tend to use the supraglottic laryngeal muscles to compensate for their voice [66]. This might temporarily produce a normal voice. However, if this condition persists, unnecessary muscular tension arises, resulting in incorrect phonatory habits. To prevent excessive laryngeal compensatory use, vocal hygiene education on ideal pos- ture and neck exercises should be provided. Vocal hygiene also corrects inappropriate vocal habits that increase laryngeal tension, such as coughing, whispering, and yelling. For professional voice users, a microphone is recommended as an amplifying device when speaking. Drinking alcohol, coffee, or caffeinated beverages and smoking, which may result in drying of the larynx, should be avoided. For patients with combined laryngopharyngeal reflux disease, proper education to reduce the risk of reflux, such as modification of diet and lifestyle, is needed [67].

Vocal hygiene education after thyroid surgery is frequently implemented as part of voice therapy programs. SLPs should monitor patients' compensatory vocal habits and encourage them to maintain vocal hygiene and receive voice therapy [68]. For patients with VFP occurring after thyroid surgery, voice therapy by qualified SLPs specializing in the field of voice both helps the patient adjust to their "new" voice and improves voice quality to avoid the need for injection laryngoplasty (IL) or surgical treatment if the symptoms are mild [68]. In particular, for VFP occurring after thyroid surgery, early voice therapy not only improves subjective voice disorders, but also improves acoustic and auditory-perceptual voice quality and increases the possibility of improving vocal cord motility in unilateralVFP [69-71].

Although all patients undergoing surgery should receive voicerelated patient education before/after surgery, it is especially important for professional voice users with high vocal demands or patients with a high risk of voice change due to surgery [72]. Highrisk groups for voice changes after thyroid surgery include females, those of advanced age, those with larger thyroid nodules or previous surgical history, and those with gastroesophageal reflux disease. Females have a higher risk of experiencing a lowered fundamental frequency or voice change than males do [73,74]. Age is also known to be associated with the risk of voice change [32,74-76], as voice and swallowing function are known to de- 
cline after surgery in patients over 50 , and the odds ratio (OR) appears to increase by $5 \%$ as the age increases by 1 year [77]. The risk of VFP is higher if the thyroid nodule is larger than $3.5 \mathrm{~cm}$ on ultrasound or the patient has a previous surgical history. It also increases as the T-stage increases in malignancy [32,78].TT poses a higher risk of voice abnormalities after surgery than lobectomy [79]. In addition, the risk of voice abnormalities increases with a combination of neck dissection, especially central resection. $[74,75,78,80]$. Gastroesophageal reflux due to decreased function of the upper esophageal sphincter after surgery may also cause unfavorable changes [81].

\section{$K Q 4$. Does perioperative systemic corticosteroid administration benefit voice quality after thyroid surgery?}

Population: patients undergoing thyroid surgery Intervention: systemic corticosteroid administration Comparison: no administration of systemic steroid Outcome: improvement of postoperative voice quality

\section{Recommendation}

Systemic corticosteroid administration is not recommended to improve voice quality after thyroid surgery (strong recommendation, high-quality evidence).

Expert opinion $(n=57)$ : fully agree $(27,47.4 \%)$, agree $(17$, $29.8 \%)$, neither agree nor disagree $(8,14.0 \%)$, disagree $(8$, $14.0 \%)$, fully disagree $(5,8.8 \%)$

Corticosteroid administration for facial nerve paralysis and idiopathic sudden sensory neural hearing loss has been reported to decrease the symptom duration and improve the prognosis [8284]. Although their effects have not yet been proven, corticosteroids are used empirically to enhance voice quality after thyroid surgery [82]. However, systemic steroids should only be used if there is strong evidence of a benefit as they induce adverse effects.

Wang et al. [85] analyzed the benefits of intraoperative corticosteroids for reducing RLN palsy. They assigned 295 prospectively enrolled patients to steroid use and non-use groups in the first and second halves of the study period, respectively. They assessed the RLN palsy rate with the number of nerves at risk (NAR) and demonstrated no differences in the postoperative temporary or permanent RLN palsy rate and recovery days. Worni et al. [86] conducted an RCT to evaluate the effects of a single preoperative steroid on thyroid surgery. The outcome indicators were postoperative nausea, pain, and vocal function. They found no differences between the two arms in the voice disturbance index, although the steroid treatment arm showed a higher VAS score and mean vocal frequency $\left(\mathrm{F}_{0}\right)$ on the first postoperative day. However, Feroci et al. [87] failed to show a significant difference in the VAS score between the two groups. An RCT conducted by Nasiri et al. [88] revealed that intravenous dexamethasone administration before surgery significantly decreased the voice impairment score on the first day after surgery, but not on the seventh day. Despite the inconsistent findings regarding the effects of steroid treatment on postoperative voice quality, those studies showed that steroid administration effectively reduces pain, nausea, and vomiting after surgery. Recent meta-analyses concluded that there was insufficient evidence to claim that perioperative systemic steroids effectively improve voice outcomes after thyroid surgery [89-91].

\section{KQ 5. What are the surgical techniques to preserve the EBSLN for voice preservation during thyroidectomy?}

Population: patients undergoing thyroid surgery

Intervention: identification of the EBSLN

Comparison: no identification of the EBSLN

Outcome: preservation of voice

\section{Recommendation}

The surgeon should carefully dissect through the avascular plane between the superior pole of the thyroid glands and the cricothyroid muscle and ligate the vessel pedicles near the thyroid capsule to preserve the EBSLN (strong recommendation, moderate-quality evidence).

Expert opinion ( $\mathrm{n}=57)$ : fully agree $(48,84.2 \%)$, agree $(8$, $14.0 \%$ ), neither agree nor disagree (0), disagree (0), fully disagree $(0)$, no response $(1,1.8 \%)$

The EBSLN, a branch of the vagus nerve, is the motor nerve to the cricothyroid muscle, an essential tensor of the vocal folds. EBSLN injury results in an inability to reach high pitches, loss of ability to project the voice, and vocal fatigue during prolonged speech $[14,15,92]$. The EBSLN reaches the larynx with several variations within $1 \mathrm{~cm}$ of the superior pole [93]. Surgeons must be familiar with the anatomic variations between the EBSLN and the superior thyroid artery because these variations influence the risk of injury during thyroidectomy. Visual identification of the EBSLN is more challenging during thyroidectomy than visualization of the RLN. It is vital for dissection to begin through the avascular plane between the inner superior pole of the thyroid glands and cricothyroid muscle. Dissection then continues until individual ligation and dissection of the vessel pedicles near the thyroid capsule. This method effectively reduces the possibility of injury to the EBSLN, even when it is adherent to or passes between the branches of the superior thyroid artery [94]. The energy devices that have been widely used in recent years do not appear to be effective for preserving the EBSLN [95]. 
KQ 6. What are the surgical techniques to preserve the RLN for voice preservation during thyroidectomy?

Population: patients undergoing thyroid surgery

Intervention: identification of the RLN

Comparison: no identification of the RLN

Outcome: preservation of voice

\section{Recommendations}

1. The surgeon should identify the nerve by direct visualization during thyroid surgery to preserve the RLN (strong recommendation, moderate-quality evidence).

Expert opinion ( $\mathrm{n}=57)$ : fully agree $(46,80.7 \%)$, agree $(9$, $15.8 \%)$, neither agree nor disagree $(2,3.5 \%)$, disagree $(0)$, fully disagree (0)

2. The surgeon should perform capsular dissection of the thyroid gland to preserve the RLN during thyroid surgery (strong recommendation, moderate-quality evidence).

Expert opinion $(\mathrm{n}=57)$ : fully agree $(12,21.1 \%)$, agree $(30,52.6 \%)$, neither agree nor disagree $(9,15.8 \%)$, disagree $(5,8.8 \%)$, fully disagree $(0)$, no response $(1,1.8 \%)$

Visual identification of the RLN during thyroid surgery decreases the rate of permanent nerve injury [96-98]. The RLN branches out of the vagus nerve, upward in the subclavian artery (right) and the aortic arch (left), passes upward through the groove between the esophagus and trachea, and enters the larynx. Surgeons must be familiar with the anatomic variations of the RLN to preserve the nerve. Identification of the inferior thyroid artery (ITA) as an anatomic landmark of the RLN reduces the chance of injury. The RLN most often crosses posterior to the ITA; however, a substantial proportion of RLNs travel between the branches of the ITA, making it difficult to distinguish the RLN if the vessels are sclerotic [99]. The RLN shows anatomical variation before it enters the larynx. Berry's ligament is another point at which there is a high risk of RLN injury because the RLN crosses the branches of vessels around Berry's ligament $[99,100]$. Designated capsular dissection between the thyroid gland's capsular propria and the fascia covering the visceral compartment, including the RLN, is a useful technique for preserving the nerve [101]. Zuckerkandl's tubercle can be used as an anatomic landmark to identify the RLN when it is well developed. The RLN passes almost through the medial side of the tubercle [102]. The energy devices that have been widely used in recent years do not show superiority in RLN preservation compared to conventional instruments, including monopolar or bipolar cautery $[103,104]$. Methods to locate the RLN could be different in cases of endoscopic- and robot-assisted thyroidectomy. When the trans-axillary or bilateral axillary-breast approach is applied, the triangle comprising the common carotid artery, trachea, and ITA is considered the landmark. Berry's ligament and the inferior constrictor muscle are useful landmarks for retro-auricular and trans-oral approaches because the upper pole is dissected first $[105,106]$.

$K Q 7$. Is intraoperative neuromonitoring necessary to preserve voice quality during thyroid surgery?

Population: patients undergoing thyroid surgery

Intervention: intraoperative neuromonitoring

Comparison: no intraoperative neuromonitoring

Outcome: voice preservation

\section{Recommendation}

Intraoperative neuromonitoring is useful for reducing RLN injury during thyroid surgery (strong recommendation, moderate-quality evidence).

Expert opinion $(n=66)$ : fully agree $(47,71.2 \%)$, agree $(17$, $25.8 \%)$, neither agree nor disagree $(2,3.0 \%)$, disagree $(0)$, fully disagree (0)

No consensus has been reached on whether the use of intraoperative neuromonitoring (IONM) always lowers the risk of VFP in thyroid surgery. A recent meta-analysis suggested that IONM reduces the risk of postoperative nerve damage, although a consistent conclusion was not reached in some case series [107-116]. According to a meta-analysis of randomized controlled studies, the relative risk of permanent VFP was 0.77 (95\% confidence interval [CI], 0.33-1.77), and the relative risk of temporary VFP was 0.62 (95\% CI, 0.35-1.08) under IONM [108]. The differences in outcomes related to RLN damage seem to be due to differences between study groups. In thyroid surgery, RLN damage is affected by the skill and experience of the surgeon, reoperation, thyroid cancer or presence of a huge goiter, posterior extra-thyroid capsular extension, and the degree of central lymph node metastasis [117]. Bai and Chen [107] reported that IONM reduced the risk of RLN palsy by approximately $20 \%$ when compared to cases performed by inexperienced surgeons.

In particular, when TT is performed, bilateral VFP can cause serious side effects, such as dyspnea; therefore, IONM is helpful [107]. In the cases of recurrent cancer or the presence of a tumor around the RLN, it is difficult to identify the nerve due to tumor tissue or scars from the previous surgery. In a meta-analysis of patients with recurrent disease, IONM reduced the risk of permanent RLN injury by approximately $55 \%$ (risk ratio, 0.426 ; 95\% CI, 0.196-0.925). In a meta-analysis, Wong et al. [118] showed that IONM reduced the risk of temporary RLN palsy from $4.5 \%$ to $2.5 \%$ in high-risk surgery (OR, $1.40 ; 95 \% \mathrm{CI}$, 1.12-1.79), and lowered the risk of permanent RLN palsy from $3.9 \%$ to $2.4 \%$ (OR, 1.47 ; $95 \%$ CI, $1.07-2.00)$. 
In Korea, IONM during thyroid surgery is allowed and covered by national insurance for the following conditions: recurrent thyroid cancer in the central compartment region; patients with unilateral vocal cord paralysis before surgery; thyroid cancer with definite central compartment lymph node metastasis; lesions caused by extracapsular involvement of the thyroid gland (T4); and high-risk thyroid and parathyroid surgery, such as advanced thyroid cancer, and Graves' disease, or prominent goiter. IONM in thyroid surgery is recommended for identifying the RLN status and predicting the presence of RLN damage, especially for high-risk patients or when performed by inexperienced surgeons because it is thought that IONM could lower the risk of RLN palsy after thyroid surgery.

\section{KQ 8. Does intraoperative RLN reinnervation improve the postoperative voice quality?}

Population: patients with unilateral RLN injury during thyroidectomy

Intervention: re-innervation of RLN

Comparison: no re-innervation

Outcome: voice quality

\section{Recommendation}

The surgeon should consider RLN reinnervation if the RLN is transected during surgery (strong recommendation, moderate-quality evidence).

Expert opinion ( $n=57)$ : fully agree $(29,40.4 \%)$, agree $(24$, $42.1 \%)$, neither agree nor disagree $(10,17.5 \%)$, disagree $(0)$, fully disagree (0)

Apparent unilateral RLN injury may occur during thyroid surgery when the RLN is retracted or sacrificed due to abutting or invasive cancer. In those cases, the surgeon should consider additional surgery for voice improvement, including intraoperative RLN reinnervation and/or intra- or postoperative medialization laryngoplasty, such as IL, medialization thyroplasty (MT), or arytenoid adduction (AA) (see KQ 11) [119-123]. Reinnervation surgery has some distinct advantages over other medialization procedures: it is usually conducted in conjunction with thyroid surgery and does not require any preparation of additional instruments, surgical drapes, and implant materials; and it helps maintain muscle bulk and tension of the vocal folds after VFP [119,124-127]. However, various forms of synkinetic reinnervation and aberrant reinnervation of abductor/adductor muscle fibers may appear during regeneration, which may worsen the voice quality after surgery. It also takes considerable time (usually 3 to 6 months) to connect sufficient axons with the vocal muscles $[128,129]$. Nevertheless, RLN reinnervation is considered a useful option for maintaining long-term voice quality and is considered to be the standard technique for long-term voice improvement in cases of an apparent transection of the RLN during thyroid surgery $[119,124,125]$. In a multicenter randomized trial, Paniello et al. [125] demonstrated that reinnervation surgery showed better voice outcomes, particularly in younger patients ( $<52$ years) compared to elderly patients ( $>52$ years), as well as in a group of patients of the same age who received medialization laryngoplasty. Lee and Park [127] reported that reinnervation showed better long-term voice outcomes than voice results at 36 months post-IL.

A combination of medialization laryngoplasty and reinnervation may be required for better voice improvement $[121,128]$ because patients may be at risk of continuing hoarseness and aspiration with reinnervation surgery only. Combining IL or MT during surgery may offer immediate voice improvement after surgery; however, intraoperative medialization procedures often result in suboptimal voice outcomes compared with postoperative procedures. Furthermore, if contralateral RLN damage occurs simultaneously, intraoperative IL or MT may cause respiratory difficulty after thyroid surgery $[120,128,130]$. Although AA has been combined with IL or MT, it should only be performed as a second-stage operation after re-evaluating voice quality, vocal fold atrophy, and the level of difference of vocal folds after paralysis because it is a permanent intervention [128,130-132].

RLN reinnervation techniques include primary anastomosis, nerve graft (ansa cervicalis, hypoglossal nerve, or vagus nerve to RLN), and neuromuscular pedicle graft [130,133-135]. When the damaged nerve's cutting edges are exposed and tension-free anastomosis is possible, primary anastomosis is easy to perform. The cutting edges of the epineurium are connected with 9-0 nylon or adhesive glue. If the nerve defect is long $(>5 \mathrm{~mm})$ due to tumor invasion and a tension-free suture is challenging, nerve graft methods using the ansa cervicalis, greater auricular nerve, transverse cervical nerve, or supraclavicular nerve are better options. Zheng et al. [123] reported that the ansa cervicalis is a good material for a free nerve graft, as it is easy to find in the same surgical field and harvest with few side effects. The surgeon can choose reinnervation between the ansa cervicalis and distal part of the RLN instead of a free nerve graft $[130,136]$. AnsaRLN neurorrhaphy requires one anastomosis between the ansa cervicalis and the distal portion of the RLN.This method can be applied even if the proximal stumps of the RLN are not identified or applied to the contralateral RLN by rotating and repositioning the ansa cervicalis. Ansa-RLN neurorrhaphy has reportedly shown better voice outcomes compared to other neurorrhaphy options $[128,137]$. When RLN damage occurs at the cricothyroid junction, reinnervation can be performed to expose the RLN branch entering the larynx by incising 0.5 to $1 \mathrm{~cm}$ of the inferior pharyngeal constrictor and removing the inferior horn of the thyroid cartilage $[120,128,137]$. 


\section{Postoperative management KQ 9. Is a postoperative laryngeal visual examination necessary?}

Population: patients undergoing thyroid surgery Intervention: preoperative laryngeal examination Comparison: no preoperative laryngeal examination Outcome: detection rates of preoperative laryngeal abnormalities

\section{Recommendation}

1. The clinician should check patients' voice after thyroid surgery (strong recommendation, moderate-quality evidence).

Expert opinion ( $n=73)$ : fully agree $(41,56.2 \%)$, agree $(22,30.1 \%)$, neither agree nor disagree $(5,6.8 \%)$, disagree $(4,5.5 \%)$, fully disagree $(0)$, no response $(1,1.4 \%)$

2 . The clinician should examine the vocal fold status of patients with voice change after thyroid surgery (strong recommendation, moderate-quality evidence).

Expert opinion ( $n=57)$ : fully agree $(43,75.4 \%)$, agree $(11,19.3 \%)$, neither agree nor disagree $(2,3.5 \%)$, disagree $(1,1.8 \%)$, fully disagree $(0)$

Approximately $30 \%-80 \%$ of patients experience voice changes immediately after surgery. Symptoms range from non-specific, including weakened vocal strength or difficulty maintaining long utterances, to severe hoarseness [7,10-12]. It is notable that patients may present with voice change after thyroid surgery, even without damage to the EBSLN and RLN. Therefore, it is necessary to assess the voice status of all patients after thyroid surgery, even if the RLN was safely preserved [7,10-12]. A comfortable, non-invasive method of screening is patient self-assessment (see KQ 2) [138]. A breathy voice requires prompt laryngeal evaluation, indicating VFP.

According to a systematic review of 27 articles investigating 25,000 patients after thyroid surgery, the incidence of temporary and permanent RLN palsy was $9.8 \%(1.4 \%-38.4 \%)$ and $2.3 \%$ ( $0 \%-18.6 \%)$, respectively. The RLN palsy rate varied widely according to the method of larynx examination [13]. Among the various laryngeal examination methods, the flexible laryngoscope is the most effective (see KQ 1) [139].

Early recognition of postoperative VFP may enable an early intervention and improve long-term clinical efficacy by reducing muscle atrophy of the vocal folds or secondary compensatory dysfunction, which will decrease voice and swallowing complications, thereby improving patients' QOL [68]. The optimal timing of visual laryngeal examinations following thyroid surgery varies in the literature. Dionigi et al. [140] compared the efficacy of laryngoscopy on the operative day and postoperative days 2 and 14 . On postoperative day 2 , laryngoscopy detected $6.7 \%$ of
VFP cases, while at 14 days, only $2.5 \%$ of paralysis cases were diagnosed. Based on these observations, they suggested early laryngeal visual examination after thyroid surgery. Delayed VFP may occur after 7 postoperative days. Bures et al. [141] examined 1,183 NAR (41\%) and found late-onset VFP in 41 (0.1\%). The American Academy of Otolaryngology-Head and Neck Surgery recommends that clinicians document voice assessment between 2 weeks and 2 months following thyroid surgery [6]. The interval until performing the post-surgery laryngeal examination should not exceed 6 months [142,143]. It is also essential to regularly track patients' voice status after surgery and to check the condition of the larynx through a laryngeal examination if there is any voice alteration. When VFP is diagnosed after thyroid surgery, serial laryngeal examinations are important because spontaneous recovery of neural function may occur within 6 to 12 months after surgery (see KQ 11).

\section{$K Q$ 10. Is a multidimensional voice assessment necessary after thyroid surgery?}

Population: patients who underwent thyroid surgery

Intervention: postoperative voice assessment

Comparison: no postoperative voice assessment

Outcome: usefulness of the assessment

\section{Recommendations}

The clinician or SLP should consider a multidimensional voice assessment for patients with voice problems after thyroid surgery (strong recommendation, moderate-quality evidence).

Expert opinion ( $\mathrm{n}=73)$ : fully agree $(45,61.6 \%)$, agree $(20$, $27.4 \%)$, neither agree nor disagree $(7,9.6 \%)$, disagree $(1$, $1.4 \%)$, fully disagree $(0)$

If any abnormalities are detected immediately after surgery on voice screening and laryngeal visual inspection, an objective voice assessment is required $[11,20,37,144]$. In those cases, the patient's voice should be assessed using specialized bedside voice assessment tools from a multidimensional perspective for the following reasons. First, clinicians or SLPs can assess voice abnormalities with spontaneous speech. During spontaneous speech, clinicians or SLPs check voice quality, including difficulty in phonation, the severity of hoarseness, irregularity of breathing, overall pitch, and loudness [44,45,145]. Second, clinicians or SLPs can evaluate voice quality while the patient reads the "San-chaek" or "Ga-eul" paragraphs, which are commonly used in voice assessments. Other familiar sentences like the national anthem are a good alternative $[44,45,49]$. During this task, clinicians or SLPs confirm the patient's voice status, including the presence of voice break, the degree of hoarseness, the 
pitch, and the volume of the voice $[49,146]$. Third, clinicians or SLPs can evaluate the difficulty of high-pitched phonation while the patient says /ah/ in a falsetto with comfortable loudness. This task indicates the voice range profile (VRP), used to determine the range of vocal pitch and loudness. If the patient cannot produce a sufficiently high pitch phonation, further voice assessments are necessary $[12,45,49,146]$. Fourth, clinicians or SLPs can measure the duration of time for which the patient can vocalize the /ah/ sound at a comfortable pitch, called the maximum phonation time (MPT). This task is simple, and phonatory problems related to breathing are easily assessed. A significant decrease compared to the preoperative measured time or an MPT shorter than 3 seconds indicates a need for further assessment $[7,12,37,49,144]$. Finally, the clinicians or SLPs can check for choking during eating or drinking, a sign of RLN damage $[11,45,147]$.

Even though various time points have been suggested, postoperative voice assessment is most likely within 2 weeks to 2 months after surgery $[11,20,37,147,148]$. Tools for voice assessment include subjective questionnaires, perceptual measures, and acoustic and aerodynamic assessments. Questionnaires that are currently in wide use include the VHI, VFI, Voice Symptom Scale, and VAPP, which have been validated in the Korean language and are easily accessible through the internet. The examiners may select the proper questionnaire according to the clinical situation, considering the questionnaire's features $[7,10,20,76,145,148$ 152]. The VAPP is useful as a screening test because it provides cutoff scores for dysphonia groups [153]. The GRBAS scale has proven its usefulness in various reports, showing independence of the examiner's proficiency level and high inter-rater reliability (see KQ 2) [44,45]. Acoustic analyses evaluate voice irregularities (the degree of harshness), including $\mathrm{F}_{0}$ (fundamental frequency, $\mathrm{Hz}$ ), jitter (\%), shimmer (\%), and the speaking fundamental frequency $\left(\mathrm{SF}_{0}, \mathrm{~Hz}\right)$. Multi-Dimensional Voice Program, a submodule program of the Computerized Speech Lab (CSL), is the most common acoustic evaluation tool. Praat is free software that can be used to measure various acoustic parameters.

When the patient shows difficulty producing short utterances, MPT is a useful measure $[44,149,154-156]$. If the patient experiences difficulties with long utterances after surgery, measuring the cepstral peak prominence (CPP) through cepstral analysis aids in the diagnosis $[44,45,156,157]$. CPP is inversely proportional to the "breathiness" parameter, and can be measured with the SpeechTool program that can be downloaded from the homepage of Hillenbrand (https://homepages.wmich.edu/ hillenbr/) or with Analysis of Dysphonia in Speech and Voice, a sub-module program of the CSL $[44,45,72,158-160]$. Studies on normative CPP data in Korean adults with normal and pathological voices have also been reported [161-163].VRP measures the pitch and amplitude ranges and is closely correlated with subjective questionnaires for thyroid surgery patients $[5,79]$. The combination of voice assessment tools may vary depending on voice charac- teristics, clinical situations, and institutional facilities. When detecting significant abnormalities in voice assessment, clinicians provide proper medical or surgical interventions or refer patients to a specialized institution to improve voice quality (see KQs 11-14) $[6,10,144,145,151,160]$.

\section{KQ 11. Are vocal fold medialization procedures necessary for patients with unilateral VFP after thyroid surgery?}

Population: patients with unilateral VFP after thyroid surgery Intervention: vocal fold medialization

Comparison: not performing vocal fold medialization

Outcome: improvement of postoperative voice quality

\section{Recommendations}

1. Close observation for 6-12 months is feasible for patients with unilateral VFP with low vocal demands and no risk of aspiration after thyroid surgery (strong recommendation, moderate-quality evidence).

Expert opinion $(\mathrm{n}=66)$ : fully agree $(23,34.8 \%)$, agree $(39,59.1 \%)$, neither agree nor disagree $(1,1.5 \%)$, disagree $(2,3.0 \%)$, fully disagree $(0)$, no response $(1,1.5 \%)$

2. Vocal fold medialization is recommended to improve voice quality and reduce aspiration for patients with unilateral VFP after thyroid surgery (strong recommendation, moderate-quality evidence).

Expert opinion ( $\mathrm{n}=66)$ : fully agree $(18,27.3 \%)$, agree $(28,42.4 \%)$, neither agree nor disagree $(16,24.2 \%)$, disagree $(2,3.0 \%)$, fully disagree $(0)$, no response $(2,3.0 \%)$

The management of patients with unilateral VFP after thyroid surgery is similar to the general protocols for unilateral VFP management. If the cause of nerve damage following thyroid surgery is clear, the initial plan should be established accordingly. Clinicians could choose to "wait-and-see" in patients with low vocal demand, few VFP complications, and no apparent RLN injury $[164,165]$.The recovery time of neural function may depend on the injury type (traction or pressure injury) and the instruments used (cold instruments or electrocauterization) [166]. In general, recovery of VFP after thyroid surgery occurs within 2 to 3 months and is less likely to occur after 6 to 12 months [167170]. During the waiting time, clinicians may be able to conduct IL with absorbing materials and/or voice therapy (see KQ 14) to reduce voice problems.

Various treatment options exist in the presence of a clear nerve section, such as tumor invasion during surgery. The surgeon could choose among nerve grafts (see KQ 8), IL, laryngeal framework surgery (LFS), such as MT and AA, and combinations of these treatments. Although some procedures, such as IL, and MT, could be performed in conjunction with surgery, it is usually recom- 
mended to wait a couple of months before performing LFS because the precise vocal fold position will be obvious after mucosal swelling has subsided and muscular atrophy has progressed. However, IL can be performed using temporary injection materials to improve voice quality during the early period of VFP before choosing permanent treatment [133]. A recent meta-analysis demonstrated that early IL continues to have clinical effects even after the materials are absorbed, reducing the need for permanent LFS [171]. Furthermore, if patients complain of voice problems or aspiration symptoms, medialization procedures should be considered in the early postoperative period [172], because early interventions will help patients return to work, adapt to society, and improve their QOL [142]. Patients with advanced age or comorbid lung diseases may have an increased risk of aspiration and dysphagia and need to be carefully observed after surgery, although the risk of aspiration from unilateral VFP after thyroid surgery is not severe. Although several tools are available to evaluate the degree of aspiration, including videofluoroscopic swallowing studies and fiberoptic endoscopic examinations of swallowing, they are cumbersome both for patients and clinicians. Clinicians usually choose IL based on patients' symptoms and laryngoscopic findings instead of a precise evaluation of the degree of aspiration.

Injection materials for IL are divided into short- and long-acting materials. Short-acting materials include gelatin, collagenbased products, carboxymethylcellulose, and hyaluronic acid (HA). Those materials have been reported to last up to 2 to 6 months. Long-acting materials include calcium hydroxyapatite (CaHA) and polymethylmethacrylate microspheres in bovine collagen. They can be maintained for more than 2 years [173]. Proper selection of the injection material depends on the type of nerve injury. For cases with an unknown prognosis of nerve recovery, it is reasonable to choose a short-acting material, of which HA is the most commonly used. HA has several advantages over other temporary materials, such as few foreign body reactions and no need for a prior skin prick test. When a permanent nerve injury is suspected, long-acting materials such as CaHA are considered. However, any remaining injection materials may cause a foreign sensation when VFP has recovered [174].

The technique for vocal fold injection following thyroid surgery is similar to that of unilateralVFP from any other cause. The initial injection starts with the posterior glottis and proceeds into the middle portion of the vocal fold. The ideal injection location is slightly lower than the vocal fold's free margin and into the thyroarytenoid muscle. Superficial injection into the lamina propria may interfere with the vibration of the vocal folds and worsen the voice quality. Over-injection by $15 \%-30 \%$ is recommended, considering the extent of subsequent absorption. Following thyroid surgery, surgical field fibrosis and adhesion may hinder the identification of surgical landmarks for IL, resulting in difficulty finding the exact injection site. For those cases, it is helpful to perform IL under general anesthesia rather than local anesthesia or to use the trans-thyroid cartilage or trans-thyrohyoid membrane approach under local anesthesia. When choosing the cricothyroid approach, several trial injections from the thyroid cartilage to the cricoid cartilage may be needed. The clinician may identify the proper injection site with a step-down injection by visualizing the needle tip sticking out under the mucosa below the glottis with the laryngoscope.

LFS is used to treat permanent unilateral VFP [125]. LFS achieves a median position of the paralyzed vocal folds by manipulating the laryngeal tissue with transplantable implants or repositioning of the arytenoid [131]. In MT, an implant is inserted through the window in the thyroid cartilage to reduce the glottal gap. It offers permanent vocal fold medialization, but is categorized as a reversible procedure because clinicians can remove the implant if sub-optimal voice outcomes or complications occur. Local anesthesia is preferred to produce optimal results. Clinicians adjust the implant position by inducing vocalization during surgery. In unilateral VFP patients with mild voice symptoms, IL substitutes for a proportion of MT. However, MT is still a treatment choice for patients with moderate to severe glottal insufficiency (glottic gap $\geq 2 \mathrm{~mm}$ during phonation) or combined dysphagia symptoms. Previous studies reported that MT showed similar short- and long-term voice outcomes and a lower reoperation rate than that of IL [175-177]. Fang et al. [178] reported that the initial large glottic gap might be a predictor for converting to MT. Currently used implant materials include the silicone block, Gore-Tex strip, and VoCom [179-181]. According to the survey results reported by Young et al. [182], silicone blocks and Gore-Tex are the most commonly used implants in Korea.

AA induces a neutral position of the paralyzed vocal fold by manipulating the arytenoid cartilage's muscular process [183]. AA is designed to correct a posterior glottic gap or a vertical level difference, which is challenging to correct with IL or MT. MT corrects the vocal fold's position and volume, while AA adjusts its tension, length, and height. Clinicians usually supplement MT with AA for a posterior glottic gap or existing vertical level difference, expecting suboptimal voice outcomes when applying MT only. Controversy persists regarding the effectiveness of performing MT and AA simultaneously. A systematic review by Chester and Stewart [184] reported no additional benefit in subjective or objective outcomes when applying AA together with MT. However, it was also reported that the surgical outcome was better in patients undergoing MT and AA than in the MT-alone group [185]. In particular, in patients with a large posterior glottic gap, simultaneous AA and MT showed better voice improvement results than MT alone [186]. Another study showed that AA combined with MT had no benefit for reducing the glottic gap or correcting the vertical level difference in comparison to MT only [187]. However, in their study, the AA with MT group presented a wider glottic gap and a greater level of difference. 


\section{$K Q$ 12. Is surgical treatment necessary for patients with bilateral VFP} after thyroid surgery?

Population: patients with bilateral VFP after thyroid surgery Intervention: surgical treatment

Comparison: no surgical treatment

Outcome: maintenance of airway patency

\section{Recommendation}

Clinicians should provide appropriate management to maintain respiratory function for patients with bilateral VFP (strong recommendation, moderate-quality evidence).

Delphi consensus $(n=66)$ : fully agree $(44,66.7 \%)$, agree $(20,30.3 \%)$, neither agree nor disagree $(2,3.0 \%)$, disagree $(2$, $3.0 \%)$, fully disagree $(0)$

With the development of surgical skills (see KQs 5-7), the incidence of bilateral VFP after thyroid surgery has decreased. Symptoms vary depending on the degree of gap between the paralyzed vocal folds, ranging from voice changes to shortness of breath, wheezing, and swallowing difficulty. Patients may present with only airway symptoms with a normal voice. Postoperative laryngoscopy confirms the presence of bilateral vocal fold immobility. CT and laryngeal electromyography help distinguish immobility from nerve injury [188,189].

Bilateral VFP treatment aims to maintain a patent upper respiratory tract and make daily activities possible. The treatment modality and timing of surgery for bilateral VFP following thyroid surgery are determined according to the possibility of nerve recovery, accompanying symptoms, and the degree of the objectively evaluated vocal fold gap. If the patients' vocal fold gaps are sufficient to maintain breathing and mild airway symptoms, conservative treatment (e.g., close observation, oxygen supply, and humidity maintenance) is possible. Clinicians may inject botulinum toxin into the vocal folds to widen the gap and control airway problems [190-192]. However, if a patient experiences upper respiratory tract obstruction, it is necessary to secure airways through surgical treatment $[58,193]$. Surgical treatment includes bypassing the glottic obstruction and glottic widening. Tracheostomy is a safe and easy method of bypassing the glottic obstruction, and it is the method most commonly used to treat bilateral VFP. Glottal displacement through arytenoid suture lateralization is a reversible method for expanding a glottal obstruction [194,195].

As alternative methods for widening the airway, laser cordotomy or arytenoidectomy can be conducted for reducing respiratory compromise in patients with bilateral VFP [196-198]. The airway can be widened stepwise in the order of arytenoid suture lateralization, cordotomy, and arytenoidectomy. Partial arytenoidectomy may maintain the airway while retaining voice quality, with a low chance of complications and morbidity [196,197]. Before performing arytenoid suture lateralization, it is crucial to confirm that there is no arytenoid fixation as a result of adhesion. Therefore, this procedure is generally recommended at the early stage of VFP, when the arytenoid cartilage is mobile. If the suture is removed within 10 weeks after arytenoid suture lateralization, long-term vocal fold damage can be avoided. However, maintaining the suture for more than 6 months causes irreversible changes in the vocal fold position [58]. Irreversible surgery can be considered when the VFP is unlikely to recover [58].

\section{$K Q$ 13. Is postoperative neck exercise needed to improve neck discomfort in patients who undergo thyroid surgery?}

\author{
Population: thyroidectomy patients \\ Intervention: neck exercise \\ Comparison: no neck exercise \\ Outcome: improvement of neck discomfort
}

\section{Recommendation}

Neck exercise may help to reduce postoperative neck discomfort after thyroid surgery (weak recommendation, lowquality evidence).

Expert opinion $(n=57)$ : fully agree $(16,28.1 \%)$, agree $(31$, $54.4 \%)$, neither agree nor disagree $(10,17.5 \%)$, disagree $(0)$, fully disagree $(0)$

Approximately $80 \%$ of patients who receive thyroidectomy complain of posterior neck pain and experience a decreased range of neck flexion and extension. They have significantly more trigger points in the neck muscles, such as the scalene, sternocleidomastoid, trapezius, and levator scapulae [199]. Postoperative neck pain can vary depending on the operative position. Patients who undergo surgery with an extended neck are significantly less likely to suffer postoperative pain than patients who do not [200]. Many patients complain of pain at the operation site after thyroid surgery, as well as neck tightness, neck pressure, stiffness, and limited shoulder and neck movement. These symptoms may persist after surgery, degrading patients' QOL. Patients tend to show more severe symptoms if they do not perform neck and shoulder exercises after surgery [201]. Adhesion between the larynx and the subcutaneous tissue after a thyroid operation limits upward movement of the larynx required for swallowing and phonation, which causes voice change and neck discomfort $[6,202,203]$. A postoperative neck massage can reduce adhesions at the surgical site by increasing blood flow, thereby improving the extensibility of the neck's soft tissue [204]. In orthopedic and breast surgery, neck rehabilitation exercises are widely used to prevent shoulder movement disorders and arm edema. Such neck exercises are equally applicable for patients following thy- 
A Tilt the head to left
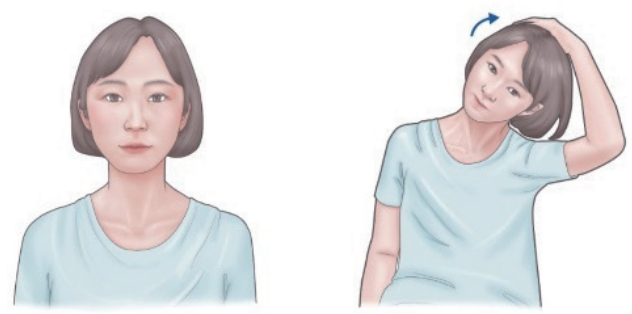

C
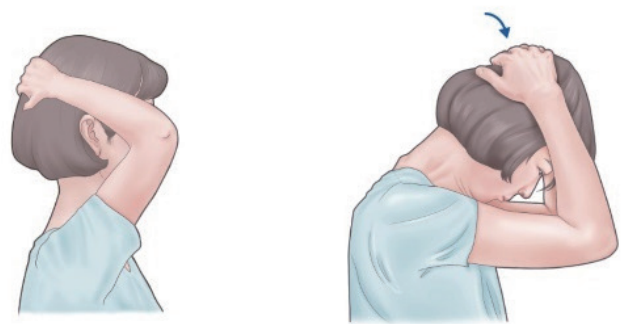

Fig. 3. (A-D) Neck exercise after thyroid surgery.

roid surgery [204].

Fig. 3 illustrates a neck exercise used after a thyroid operation. As neck exercises are intended to prevent potential neck discomfort, implementing them for all patients is still recommended. Although there are no general rules, common practice dictates that neck exercises start the day after surgery and are performed three times a day within patients' range of comfort. There are concerns about the association between neck stretching exercises and the risk of postoperative bleeding and delayed wound healing. However, most postoperative bleeding occurs prior to the first postoperative day and rarely occurs after neck exercises begin. No difference was found in wound healing between patients with neck exercise and non-exercise controls; thus, it can be concluded that neck exercise does not induce aesthetic problems by aggravating scars [201].

Another study compared neck pain, disability score, and neck sensitivity a week and a month postoperatively between a group that did not perform neck stretching exercises and a group in which neck stretching exercises were initiated the day after surgery. A week after the operation, the stretching neck group showed a significant improvement in neck pain, disability score, and neck sensitivity. However, there was no significant difference between the two groups a month after surgery [205]. A study by Kim et al. [206] evaluated the effect of home-based exercise in patients taking hormone supplement therapy after TT, and found that the exercise group showed improved QOL with less fatigue and anxiety. The home-based 12-week exercise regimen consisted of
B Tilt the head to right
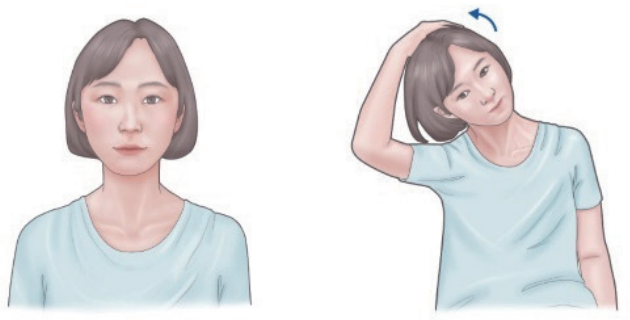

(D)

Tilt the head upwards
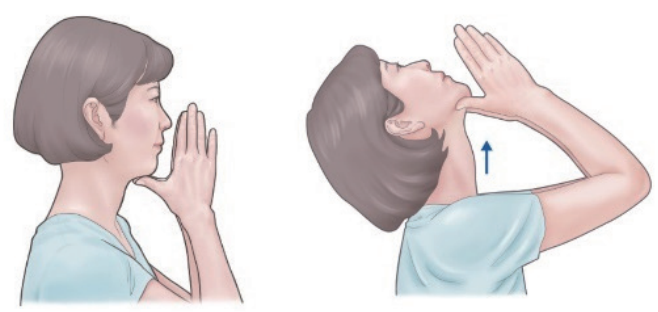

aerobic exercise (walking), resistance exercises (upper body exercises, lower body exercises), and flexibility exercises. Another study by Genc et al. [207] investigated the effects of kinesiotaping on the cervical spine for neck pain and neck movement after thyroid surgery. They reported that applying kinesiotape reduced the consumption of painkillers; however, there was no impact on neck pain, range of neck movement, and neck disability index.

$K Q$ 14. Is voice therapy necessary for optimizing voice outcomes and improving voice-related QOL after thyroid surgery?

Population: patients with thyroid surgery

Intervention: voice therapy

Comparison: no voice therapy

Outcome: improvement in voice and QOL

\section{Recommendation}

Voice therapy is helpful to improve voice quality and QOL for patients with voice problems after thyroid surgery (weak recommendation, moderate-quality evidence).

Expert opinion ( $\mathrm{n}=57)$ : fully agree $(18,31.6 \%)$, agree (31, $54.4 \%)$, neither agree nor disagree $(7,12.3 \%)$, disagree $(0)$, fully disagree (0) 
(A)

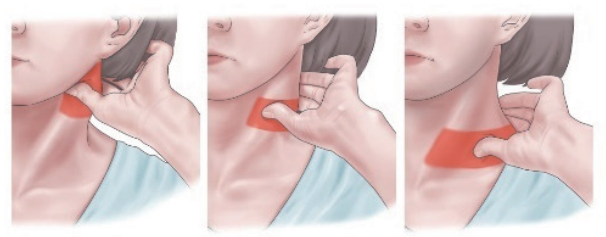

1. Slightly tilt the neck

2. Hold the sternocleidomastoid muscles with finger

3. Massage from upper to lower neck
B

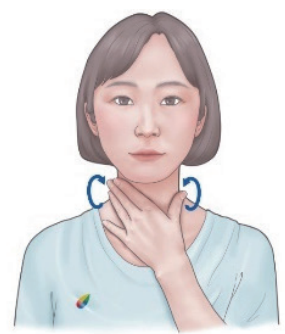

1. Gently wrap the neck throughout the palm

2. Massage from front to back like drawing a circle.

3. Massage from upper to lower neck

Fig. 4. (A, B) Laryngeal massage after thyroid surgery.

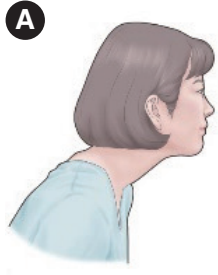

Straighten of the neck, waist and shoulders
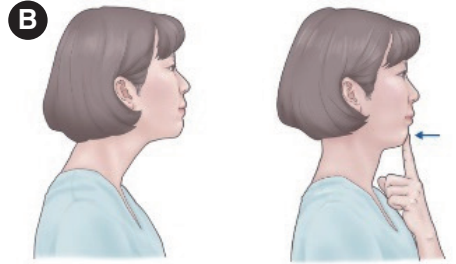

Don't let the chin forward
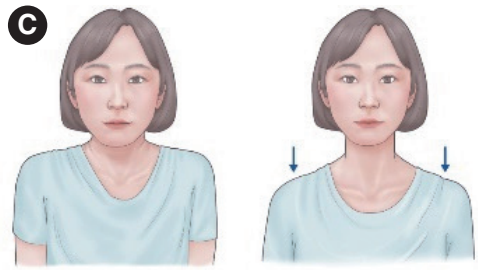

Relax the shoulder

Fig. 5. (A-C) Neck posture adjustments after thyroid surgery.

In the postoperative period, patients' responses to voice changes vary, ranging from not being aware of or ignoring the problem to requiring treatment, considering the QOL [208]. SLPs can apply problem-oriented voice therapy techniques to patients who complain of voice-related symptoms. Early voice therapy shows better voice outcomes and QOL than therapy started later [6,58]. The focus of voice therapy is on producing an optimal voice through appropriate adjustment and compensation for the changed laryngeal physiology [6]. For patients with vocal complaints, voice rehabilitation programs include appropriate vocal hygiene education and counseling for voice changes and voice-related anxiety. Active voice counseling and education help improve voice satisfaction and QOL by alleviating excessive anxiety or concerns about vocal conditions. They also increase patients' motivation to participate in direct voice therapy (see KQ 3).

Even without RLN injury, patients frequently present a wide variety of symptoms as a result of adhesions in the surgical field. Typical characteristics include voice change, vocal fatigue, vocal effort, changes in habitual vocal pitch, decreased vocal range, muscle cramps, and cervical stiffness such as muscle tension dysphonia $[47,48]$. Patients with unilateral VFP typically present a breathy but strained voices due to inadequate compensation of glottal insufficiency [66]. Altered laryngeal physiology makes it necessary to include neck exercise programs in voice therapy programs to prevent excessive muscle tension after surgery. Neck exercise programs consist of neck extension (Fig. 3, see KQ 13), laryngeal massage (Fig. 4), and head and neck posture adjustment (Fig. 5). The laryngeal massage starts away from the surgical site and continues to the surgical area within a pain-free range. SLPs educate patients on the proper posture to reduce muscle tension, in combination with relaxation techniques, such as abdominal breathing, yawning, sighing, and chewing [204]. In severe glottal insufficiency cases, SLPs can try inhalation phonation and pushing methods (to strengthen vocal folds. In suspected cricothyroid muscle paralysis, gradually gliding up and down the pitch range (gliding methods) may increase muscle control. In addition, proper adjustment of overall speech production subsystems, such as respiration, phonation, resonation, and articulation, can reduce excessive tension and improve vocal cord motility and resonant voice quality [208]. These techniques include vocal function exercises, the accent method, resonant voice therapy, and semi-occluded vocal tract exercises [209,210]. In particular, semi-occluded vocal tract exercises are useful for a variety of organic or behavioral voice disorders, as well as VFP, vocal fatigue, and muscle tension dysphonia after thyroid surgery [210].

Voice abnormalities due to RLN damage can be significantly improved by voice therapy alone. Even if VF medialization injection procedures or thyroplasty are planned, the effectiveness of voice improvement can be enhanced through preoperative or postoperative voice treatment [211-213]. Voice therapy should 

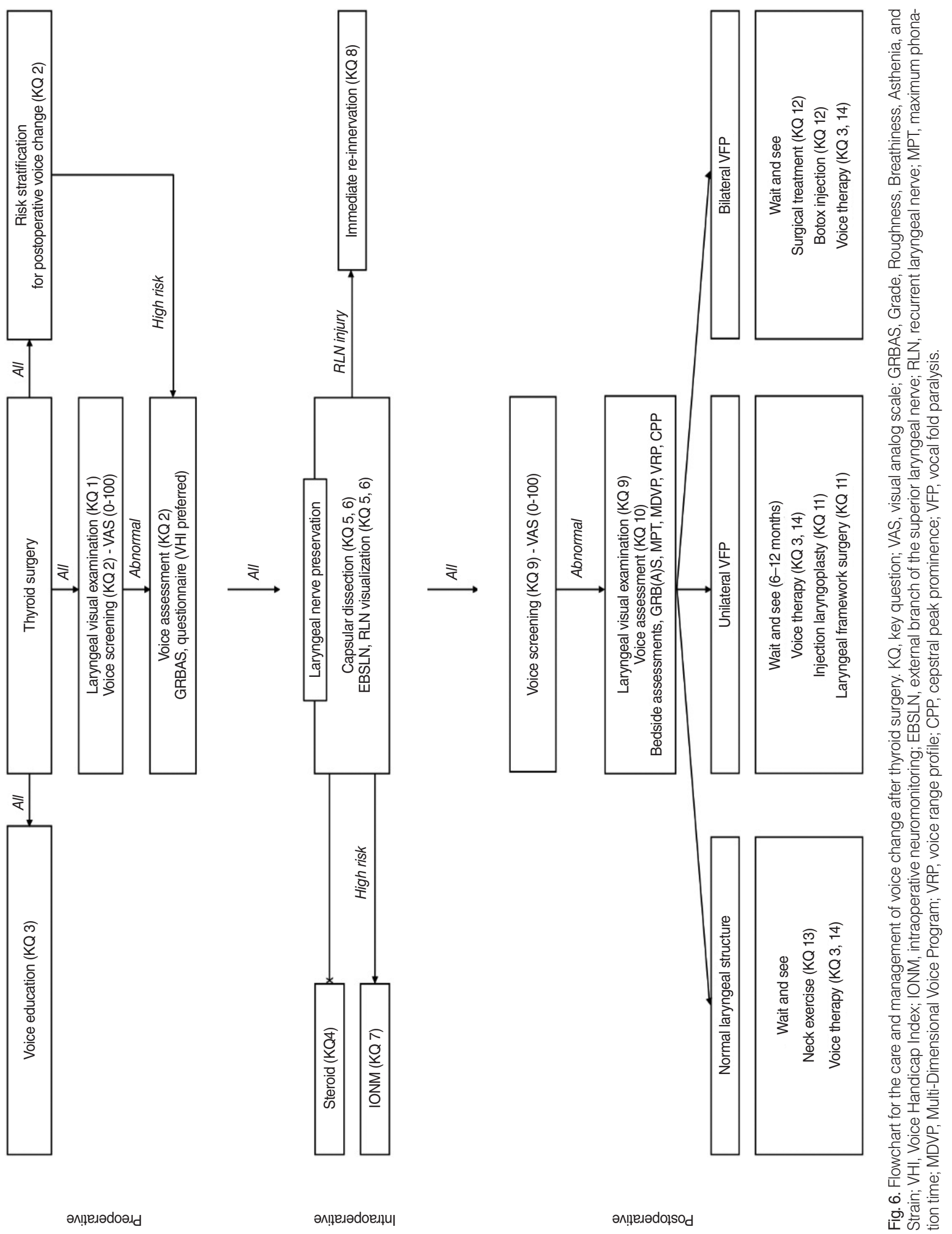
be performed as soon as possible to prevent contraction of paralyzed vocal cord muscles in the presence of RLN damage [214]. A prospective, randomized clinical trial study reported that the treatment of patients with RLN damage was more effective if electrical stimulation-supported voice treatments were performed [215].

EBSLN damage causes paralysis of the cricothyroid muscle, causing problems with the stretching, stiffening, or thinning of the vocal cords. Patients may experience hoarseness, vocal fatigue, decreased vocal loudness and pitch range, difficulty in controlling vocal intensity and pitch, and transitions from modal to highpitched falsetto $[14,15,92]$. Voice problems and voice-related discomfort or concern due to EBSLN damage can lead to muscle tension dysphonia due to inadequate compensatory behaviors. Failure to treat muscle tension dysphonia can cause prolonged voice problems and structural damage associated with effortful phonation [216]. Treatment of the damaged EBSLN focuses on voice therapy, and the behavioral approach of strengthening the cricothyroid muscle through activities such as glissando maneuvers and eliminating muscle tension dysphonia caused by inappropriate compensation is useful for voice recovery $[15,217]$.

\section{CONCLUSION}

Voice change is one of the main complaints after thyroid surgery, resulting in a decrease in QOL. The clinician should check the voice status and perform laryngeal visualization for all patients before thyroid surgery. Further voice assessments are indicated for patients with any abnormalities on voice screening and laryngeal examination, and for patients at a high risk of voice change after surgery. The clinician or SLP should educate patients before surgery about the potential risk of voice change, voice hygiene, and possible management of postoperative voice change. The effects of steroids on the prevention of voice change patients are still unclear; thus, systematic steroids are not recommended. For optimal voice outcomes, the surgeon should pay close attention to preserving the EBSLN and RLN during thyroid surgery. IONM helps identify the RLN status and predict the presence of RLN damage, especially in high-risk patients. After thyroid surgery, the clinician should check the patients' voice status. A postoperative laryngeal examination and multidimensional voice assessment are indicated for patients with voice change.

The management of RLN injuries should be tailored to the clinical circumstances. During surgery, the surgeon should consider laryngeal reinnervation if the RLN is transected and the distal stump of the RLN is available. Close observation for 6-12 months or less-invasive treatment, including voice therapy and $\mathrm{IL}$, is feasible for unilateral VFP patients with low vocal demands and no risk of aspiration after thyroid surgery. However, vocal fold medialization is recommended for patients with high vocal demand and/or aspiration. The clinician should monitor respira- tory function for patients with bilateral VFP. Neck exercise is recommended to reduce postoperative neck discomfort after thyroid surgery. A flowchart for the care and management of voice change after thyroid surgery is depicted in Fig. 6 .

\section{CONFLICT OF INTEREST}

No potential conflict of interest relevant to this article was reported.

\section{ACKNOWLEDGMENTS}

We would like to express our special thanks to the Creative Media Service of the National Cancer Center, Korea, for providing superb figures.

\section{ORCID}

Chang Hwan Ryu https://orcid.org/0000-0001-8150-5163

Seung Jin Lee https://orcid.org/0000-0001-6200-0004

Jae-Gu Cho https://orcid.org/0000-0003-0874-2271

Ik Joon Choi https://orcid.org/0000-0002-9680-3873

Yoon Seok Choi https://orcid.org/0000-0002-0616-7122

Yong Tae Hong https://orcid.org/0000-0001-7584-5823

Soo Yeon Jung https://orcid.org/0000-0001-7497-3057

JiWon Kim https://orcid.org/0000-0003-1587-9671

Doh Young Lee https://orcid.org/0000-0003-1590-8559

Dong Kun Lee https://orcid.org/0000-0002-7296-1420

GIljoon Lee https://orcid.org/0000-0002-3344-1879

Sang Joon Lee https://orcid.org/0000-0001-7513-5733

Young Chan Lee https://orcid.org/0000-0001-5577-7288

Yong Sang Lee https://orcid.org/0000-0002-8234-8718

Inn Chul Nam https://orcid.org/0000-0001-9246-1047

Ki Nam Park https://orcid.org/0000-0001-6641-3981

Young Min Park https://orcid.org/0000-0002-7593-8461

Eui-Suk Sung https://orcid.org/0000-0001-8752-3426

Hee Young Son https://orcid.org/0000-0002-2845-1423

In Hyo Seo https://orcid.org/0000-0002-2665-661X

Byung-Joo Lee https://orcid.org/0000-0001-7091-6688

Jae-Yol Lim https://orcid.org/0000-0002-3638-2632

\section{AUTHOR CONTRIBUTIONS}

Conceptualization: CHR, BJL, JYL. Data curation: all authors. Formal analysis: all authors. Methodology: CHR, SJL, JYL. Project administration: CHR, SJL, JYL. Visualization: CHR, SJL, JYL. Writing-original document: all authors. Writing-review \& editing: CHR, SJL, BJL, JYL. 


\section{SUPPLEMENTARY MATERIALS}

Supplementary materials can be found via https://doi.org/10. 21053/ceo.2021.00633.

\section{REFERENCES}

1. Jung KW,Won YJ, Kong HJ, Lee ES. Cancer statistics in Korea: incidence, mortality, survival, and prevalence in 2016. Cancer Res Treat. 2019 Apr;51(2):417-30.

2. Haugen BR,Alexander EK, Bible KC, Doherty GM, Mandel SJ, Nikiforov YE, et al. 2015 American Thyroid Association management guidelines for adult patients with thyroid nodules and differentiated thyroid cancer: the American Thyroid Association Guidelines Task Force on Thyroid Nodules and Differentiated Thyroid Cancer. Thyroid. 2016 Jan;26(1):1-133.

3. Yi KH, Lee EK, Kang HC, Koh Y, Kim SW, Kim IJ, et al. 2016 Revised Korean Thyroid Association management guidelines for patients with thyroid nodules and thyroid cancer. Int JThyroidol. 2016 Nov;9(2):59-126.

4. Ryu CH, Park B, Ryu J, Ryu YM, Jo SA, Lee YJ, et al. Development and evaluation of a Korean version of a thyroid-specific quality-oflife questionnaire scale in thyroid cancer patients. Cancer Res Treat. 2018 Apr;50(2):405-15.

5. Ryu CH, Ryu J, Ryu YM, Lee YJ, Lee EK, Kim SK, et al. Administration of radioactive iodine therapy within 1 year after total thyroidectomy does not affect vocal function. J Nucl Med. 2015 Oct; 56(10):1480-6.

6. Chandrasekhar SS, Randolph GW, Seidman MD, Rosenfeld RM, Angelos P, Barkmeier-Kraemer J, et al. Clinical practice guideline: improving voice outcomes after thyroid surgery. Otolaryngol Head Neck Surg. 2013 Jun;148(6 Suppl):S1-37.

7. de Pedro Netto I, Fae A, Vartanian JG, Barros AP, Correia LM,Toledo RN, et al. Voice and vocal self-assessment after thyroidectomy. Head Neck. 2006 Dec;28(12):1106-14.

8. Delgado-Vargas B, Lloris Romero-Salazar A, Cobeta I.Vocal changes following thyroid surgery: prospective study of objective and subjective parameters. JVoice. 2019 Jan;33(1):27-32.

9. Akyildiz S, Ogut F, Akyildiz M, Engin EZ. A multivariate analysis of objective voice changes after thyroidectomy without laryngeal nerve injury. Arch Otolaryngol Head Neck Surg. 2008 Jun;134(6): 596-602.

10. Chun BJ, Bae JS, Chae BJ, Hwang YS, Shim MR, Sun DI. Early postoperative vocal function evaluation after thyroidectomy using thyroidectomy related voice questionnaire. World J Surg. 2012 Oct; 36(10):2503-8.

11. Dixon H, Amin N, Lindisfarne E, Gibbins N, Harries M. Pre- and post-operative assessment of voice in thyroidectomy patients: an audit cycle. Clin Otolaryngol. 2012 Jul;37(S1):34-5.

12. Park JO, Bae JS, Chae BJ, Kim CS, Nam IC, Chun BJ, et al. How can we screen voice problems effectively in patients undergoing thyroid surgery? Thyroid. 2013 Nov;23(11):1437-44.

13. Jeannon JP, Orabi AA, Bruch GA, Abdalsalam HA, Simo R. Diagnosis of recurrent laryngeal nerve palsy after thyroidectomy: a systematic review. Int J Clin Pract. 2009 Apr;63(4):624-9.

14. Kierner AC, Aigner M, Burian M. The external branch of the superior laryngeal nerve: its topographical anatomy as related to surgery of the neck. Arch Otolaryngol Head Neck Surg. 1998 Mar;124(3): 301-3.

15. Orestes MI, Chhetri DK. Superior laryngeal nerve injury: effects, clinical findings, prognosis, and management options. Curr Opin
Otolaryngol Head Neck Surg. 2014 Dec;22(6):439-43.

16. Shea BJ, Grimshaw JM,Wells GA, Boers M,Andersson N, Hamel C, et al. Development of AMSTAR: a measurement tool to assess the methodological quality of systematic reviews. BMC Med Res Methodol. 2007 Feb; 7:10.

17. Kim SY, Park JE, Lee YJ, Seo HJ, Sheen SS, Hahn S, et al. Testing a tool for assessing the risk of bias for nonrandomized studies showed moderate reliability and promising validity. J Clin Epidemiol. 2013 Apr;66(4):408-14.

18. Farrag TY, Samlan RA, Lin FR, Tufano RP. The utility of evaluating true vocal fold motion before thyroid surgery. Laryngoscope. 2006 Feb;116(2):235-8.

19. Randolph GW, Kamani D. The importance of preoperative laryngoscopy in patients undergoing thyroidectomy: voice, vocal cord function, and the preoperative detection of invasive thyroid malignancy. Surgery. 2006 Mar;139(3):357-62.

20. Nam IC, Bae JS, Shim MR, Hwang YS, Kim MS, Sun DI.The importance of preoperative laryngeal examination before thyroidectomy and the usefulness of a voice questionnaire in screening. World $\mathrm{J}$ Surg. 2012 Feb;36(2):303-9.

21. Bilimoria KY, Bentrem DJ, Ko CY, Stewart AK, Winchester DP,Talamonti MS, et al. Extent of surgery affects survival for papillary thyroid cancer. Ann Surg. 2007 Sep;246(3):375-81.

22. Hiramatsu H, Tokashiki R, Nakamura M, Motohashi R, Yoshida T, Suzuki M. Characterization of arytenoid vertical displacement in unilateral vocal fold paralysis by three-dimensional computed tomography. Eur Arch Otorhinolaryngol. 2009 Jan;266(1):97-104.

23. Laeeq K, Pandian V, Skinner M, Masood H, Stewart CM, Weatherly $\mathrm{R}$, et al. Learning curve for competency in flexible laryngoscopy. Laryngoscope. 2010 Oct;120(10):1950-3.

24. Paul BC, Rafii B, Achlatis S, Amin MR, Branski RC. Morbidity and patient perception of flexible laryngoscopy. Ann Otol Rhinol Laryngol. 2012 Nov;121(11):708-13.

25. Woodson GE. Configuration of the glottis in laryngeal paralysis. I: clinical study. Laryngoscope. 1993 Nov;103(11 Pt 1):1227-34.

26. Simpson CB, Cheung EJ, Jackson CJ.Vocal fold paresis: clinical and electrophysiologic features in a tertiary laryngology practice. JVoice. 2009 May;23(3):396-8.

27. Sinclair CF, Bumpous JM, Haugen BR, Chala A, Meltzer D, Miller $\mathrm{BS}$, et al. Laryngeal examination in thyroid and parathyroid surgery: an American Head and Neck Society consensus statement: AHNS Consensus Statement. Head Neck. 2016 Jun;38(6):811-9.

28. Perros P, Boelaert K, Colley S, Evans C, Evans RM, Gerrard Ba G, et al. Guidelines for the management of thyroid cancer. Clin Endocrinol (Oxf). 2014 Jul;81 Suppl 1:1-122.

29. Dralle H, MusholtTJ, Schabram J, SteinmullerT, Frilling A, Simon D, et al. German Association of Endocrine Surgeons practice guideline for the surgical management of malignant thyroid tumors. Langenbecks Arch Surg. 2013 Mar;398(3):347-75.

30. Randolph GW, Dralle H; International Intraoperative Monitoring Study Group, Abdullah H, Barczynski M, Bellantone R, et al. Electrophysiologic recurrent laryngeal nerve monitoring during thyroid and parathyroid surgery: international standards guideline statement. Laryngoscope. 2011 Jan;121 Suppl 1:S1-16.

31. National Comprehensive Cancer Network. NCCN Clinical Practice Guidelines in Oncology (NCCN Guidelines ${ }^{\circledR}$ ): thyroid carcinoma. version 2.2020. Plymouth Meeting (PA): National Comprehensive Cancer Network; 2020.

32. Maher DI, Goare S, Forrest E, Grodski S, Serpell JW, Lee JC. Routine preoperative laryngoscopy for thyroid surgery is not necessary without risk factors. Thyroid. 2019 Nov;29(11):1646-52.

33. Zanocco K, Kaltman DJ, Wu JX, Fingeret A, Heller KS, Lee JA, et al. Cost effectiveness of routine laryngoscopy in the surgical treatment of differentiated thyroid cancer. Ann Surg Oncol. 2018 Apr; 
25(4):949-56

34. McIvor NP, Flint DJ, Gillibrand J, Morton RP. Thyroid surgery and voice-related outcomes. Aust N Z J Surg. 2000 Mar;70(3):179-83.

35. Meek P, Carding PN, Howard DH, Lennard TW. Voice change following thyroid and parathyroid surgery. J Voice. 2008 Nov;22(6): 765-72.

36. Ryu CH, Han S, Lee MS, Kim SY, Nam SY, Roh JL, et al.Voice changes in elderly adults: prevalence and the effect of social, behavioral, and health status on voice quality. J Am Geriatr Soc. 2015 Aug; 63(8):1608-14.

37. Stojadinovic A, Henry LR, Howard RS, Gurevich-Uvena J, Makashay MJ, Coppit GL, et al. Prospective trial of voice outcomes after thyroidectomy: evaluation of patient-reported and clinician-determined voice assessments in identifying postthyroidectomy dysphonia. Surgery. 2008 Jun;143(6):732-42.

38. Dejonckere PH, Bradley P, Clemente P, Cornut G, Crevier-Buchman L, Friedrich $\mathrm{G}$, et al. A basic protocol for functional assessment of voice pathology, especially for investigating the efficacy of (phonosurgical) treatments and evaluating new assessment techniques. Guideline elaborated by the Committee on Phoniatrics of the European Laryngological Society (ELS). Eur Arch Otorhinolaryngol. 2001 Feb;258(2):77-82.

39. Biddle AK, Watson LR, Hooper CR, Lohr KN, Sutton SF. Criteria for determining disability in speech-language disorders. Evid Rep Technol Assess (Summ). 2002 Jan;(52):1-4.

40. Rosen CA, Lee AS, Osborne J, Zullo T, Murry T. Development and validation of the voice handicap index-10. Laryngoscope. 2004 Sep;114(9):1549-56.

41. Morzaria S, Damrose EJ. A comparison of the VHI,VHI-10, and VRQOL for measuring the effect of botox therapy in adductor spasmodic dysphonia. JVoice. 2012 May;26(3):378-80.

42. Ma EP, Yiu EM. Voice activity and participation profile: assessing the impact of voice disorders on daily activities. J Speech Lang Hear Res. 2001 Jun;44(3):511-24.

43. Nanjundeswaran C, Jacobson BH, Gartner-Schmidt J,Verdolini Abbott K. Vocal Fatigue Index (VFI): development and validation. J Voice. 2015 Jul;29(4):433-40.

44. Ko DH. Experimental phonetics for speech-language pathologists. Seoul: Hakjisa Publisher; 2015.

45. Korean Society of Laryngology, Phoniatrics and Logopedics. Understanding of laryngology: voice, speech and swallowing. Seoul: Panmun Education; 2016.

46. Kempster GB, Gerratt BR, Verdolini Abbott K, Barkmeier-Kraemer J, Hillman RE. Consensus auditory-perceptual evaluation of voice: development of a standardized clinical protocol.Am J Speech Lang Pathol. 2009 May;18(2):124-32.

47. Kark AE, Kissin MW, Auerbach R, Meikle M. Voice changes after thyroidectomy: role of the external laryngeal nerve. Br Med J (Clin Res Ed). 1984 Nov;289(6456):1412-5.

48. Hong KH, Kim YK. Phonatory characteristics of patients undergoing thyroidectomy without laryngeal nerve injury. Otolaryngol Head Neck Surg. 1997 Oct;117(4):399-404.

49. Choi SH. Development of Korean standardized sentences on voice quality evaluation for dysphonia.Audiol Speech Res. 2018Apr;14(2): 128-42.

50. Aluffi P, Policarpo M, Cherovac C, Olina M, Dosdegani R, Pia F. Post-thyroidectomy superior laryngeal nerve injury. Eur Arch Otorhinolaryngol. 2001 Nov;258(9):451-4.

51. Song CM, Kim H, Kwon TK, Sung MW, Kim KH, Hah JH. Investigation on patients' understanding and concern about the disease and recovery rate in thyroidectomy patients to enhance satisfaction of hospitalization. Korean J Otorhinolaryngol-Head Neck Surg. 2010 Sep;53(9):557-63.

52. Chung EJ.Voice care for the post-thyroidectomy dysphonia. J Ko- rean Soc Laryngol Phoniatr Logoped. 2016 Jun;27(1):14-7.

53. Feldman-Stewart D, Capirci C, Brennenstuhl S, Tong C, Abacioglu $\mathrm{U}$, Gawkowska-Suwinska M, et al. Information for decision making by patients with early-stage prostate cancer: a comparison across 9 countries. Med Decis Making. 2011 Sep-Oct;31(5):754-66.

54. Street RL Jr, Voigt B. Patient participation in deciding breast cancer treatment and subsequent quality of life. Med Decis Making. 1997 Jul-Sep;17(3):298-306.

55. El-Banna M, Youssef G. Early voice therapy in patients with unilateral vocal fold paralysis. Folia Phoniatr Logop. 2014;66(6):237-43.

56. Abdul-Sater L, Henry M, Majdan A, Mijovic T, Franklin JH, Brandt MG, et al. What are thyroidectomy patients really concerned about? Otolaryngol Head Neck Surg. 2011 May;144(5):685-90.

57. SFORL Work Group, Santini J, Alfonsi JP, Bonichon F, Bozec A, Giovanni A, et al. Patient information ahead of thyroid surgery: Guidelines of the French Society of Oto-Rhino-Laryngology and Head and Neck Surgery (SFORL). Eur Ann Otorhinolaryngol Head Neck Dis. 2013 Dec;130(6):363-8.

58. Chen X,Wan P,YuY, Li M, XuY, Huang P, et al.Types and timing of therapy for vocal fold paresis/paralysis after thyroidectomy: a systematic review and meta-analysis. J Voice. 2014 Nov;28(6):799808.

59. Chan Y, Irish JC, Wood SJ, Rotstein LE, Brown DH, Gullane PJ, et al. Patient education and informed consent in head and neck surgery. Arch Otolaryngol Head Neck Surg. 2002 Nov;128(11):1269-74.

60. Awan SN, Helou LB, Stojadinovic A, Solomon NP. Tracking voice change after thyroidectomy: application of spectral/cepstral analyses. Clin Linguist Phon. 2011Apr;25(4):302-20.

61. Alsaffar H, Wilson L, Kamdar DP, Sultanov F, Enepekides D, Higgins KM. Informed consent: do information pamphlets improve post-operative risk-recall in patients undergoing total thyroidectomy. Prospective randomized control study. J Otolaryngol Head Neck Surg. 2016 Feb;45:14.

62. Patel CR, Cherla DV, Sanghvi S, Baredes S, Eloy JA. Readability assessment of online thyroid surgery patient education materials. Head Neck. 2013 Oct;35(10):1421-5.

63. Yeo H, Roman S, Air M, Maser C, TrapassoT, Kinder B, et al. Filling a void: thyroid cancer surgery information on the internet. World $\mathrm{J}$ Surg. 2007 Jun;31(6):1185-91.

64. Temiz Z, Ozturk D, Ugras GA, Oztekin SD, Sengul E. Determination of patient learning needs after thyroidectomy. Asian Pac J Cancer Prev. 2016;17(3):1479-83.

65. Hosoya M, Kobayashi R, Ishii T, Senarita M, Kuroda H, Misawa H, et al. Vocal hygiene education program reduces surgical interventions for benign vocal fold lesions: a randomized controlled trial. Laryngoscope. 2018 Nov;128(11):2593-9.

66. Belafsky PC, Postma GN, Reulbach TR, Holland BW, Koufman JA. Muscle tension dysphonia as a sign of underlying glottal insufficiency. Otolaryngol Head Neck Surg. 2002 Nov;127(5):448-51.

67. Krouse HJ, Reavis CC, Stachler RJ, Francis DO, O'Connor S. Plain language summary: hoarseness (dysphonia). Otolaryngol Head Neck Surg. 2018 Mar;158(3):427-31.

68. Rubin AD, Sataloff RT. Vocal fold paresis and paralysis: what the thyroid surgeon should know. Surg Oncol Clin N Am. 2008 Jan; 17(1):175-96.

69. D’Alatri L, Galla S, Rigante M, Antonelli O, Buldrini S, Marchese MR. Role of early voice therapy in patients affected by unilateral vocal fold paralysis. J Laryngol Otol. 2008 Sep;122(9):936-41.

70. Mattioli F, Bergamini G, Alicandri-Ciufelli M, Molteni G, Luppi MP, Nizzoli F, et al. The role of early voice therapy in the incidence of motility recovery in unilateral vocal fold paralysis. Logoped PhoniatrVocol. 2011 Apr;36(1):40-7.

71. Tang SS, Thibeault SL. Timing of voice therapy: a primary investigation of voice outcomes for surgical benign vocal fold lesion patients. 
JVoice. 2017 Jan;31(1):129.e1-129.e7.

72. Al-Yahya SN, Muhammad R, Suhaimi S, Azman M, Mohamed AS, Baki MM. Selective laryngeal examination: sensitivity of endocrine surgeons in screening voice abnormality. J Voice. 2020 Sep;34(5): 811.e13-811.e20.

73. Park JO, Bae JS, Lee SH, Shim MR, Hwang YS, Joo YH, et al. Multivariate analysis of risk factors in the development of a lower-pitched voice after thyroidectomy. Ann Otol Rhinol Laryngol. 2017 Feb; 126(2):117-23.

74. Vetshev PS, Yankin PL, Zhivotov VA, Poddubniy EI, Drozhzhin AY, Prokhorov VD. Risk factors and prognosis of voice disorders after surgical treatment of thyroid and parathyroid diseases. Khirurgiia (Mosk). 2019;(4):5-14.

75. Park JO, Bae JS, Lee SH, Shim MR, Hwang YS, Joo YH, et al. The long-term prognosis of voice pitch change in female patients after thyroid surgery. World J Surg. 2016 Oct;40(10):2382-90.

76. Papadakis CE, Asimakopoulou P, Proimos E, Perogamvrakis G, Papoutsaki E, Chimona T. Subjective and objective voice assessments after recurrent laryngeal nerve-preserved total thyroidectomy. J Voice. 2017 Jul;31(4):515.e15-515.e21.

77. Sahli Z, Canner JK, Najjar O, Schneider EB, Prescott JD, Russell $\mathrm{JO}$, et al. Association between age and patient-reported changes in voice and swallowing after thyroidectomy. Laryngoscope. 2019 Feb;129(2):519-24.

78. Dhillon VK, Rettig E, Noureldine SI, Genther DJ, Hassoon A, Al Khadem MG, et al. The incidence of vocal fold motion impairment after primary thyroid and parathyroid surgery for a single high-volume academic surgeon determined by pre- and immediate postoperative fiberoptic laryngoscopy. Int J Surg. 2018 Aug;56:73-8.

79. Ryu J, Ryu YM, Jung Y, Kim S, Lee YJ, Lee E, et al. Extent of thyroidectomy affects vocal and throat functions: a prospective observational study of lobectomy versus total thyroidectomy. $2013 \mathrm{Sep}$; 154(3):611-20.

80. Park YM, Oh KH, Cho JG, Baek SK, Kwon SY, Jung KY, et al. Changes in voice- and swallowing-related symptoms after thyroidectomy: one-year follow-up study. Ann Otol Rhinol Laryngol. 2018 Mar; 127(3):171-7.

81. Scerrino G, Inviati A, Di Giovanni S, Paladino NC, Di Paola V, Lo Re G, et al. Esophageal motility changes after thyroidectomy: possible associations with postoperative voice and swallowing disorders: preliminary results. Otolaryngol Head Neck Surg. 2013 Jun; 148(6):926-32.

82. Cohen SM, Lee HJ, Roy N, Misono S. Pharmacologic management of voice disorders by general medicine providers and otolaryngologists. Laryngoscope. 2018 Mar;128(3):682-9.

83. Holland NJ,Weiner GM. Recent developments in Bell's palsy. BMJ. 2004 Sep;329(7465):553-7.

84. Stachler RJ, Chandrasekhar SS, Archer SM, Rosenfeld RM, Schwartz SR, Barrs DM, et al. Clinical practice guideline: sudden hearing loss. Otolaryngol Head Neck Surg. 2012 Mar;146(3 Suppl):S1-35.

85. Wang LF, Lee KW, KuoWR, Wu CW, Lu SP, Chiang FY.The efficacy of intraoperative corticosteroids in recurrent laryngeal nerve palsy after thyroid surgery.World J Surg. 2006 Mar;30(3):299-303.

86. Worni M, Schudel HH, Seifert E, Inglin R, Hagemann M, Vorburger $\mathrm{SA}$, et al. Randomized controlled trial on single dose steroid before thyroidectomy for benign disease to improve postoperative nausea, pain, and vocal function. Ann Surg. 2008 Dec;248(6):1060-6.

87. Feroci F, Rettori M, Borrelli A, Lenzi E, Ottaviano A, Scatizzi M. Dexamethasone prophylaxis before thyroidectomy to reduce postoperative nausea, pain, and vocal dysfunction: a randomized clinical controlled trial. Head Neck. 2011 Jun;33(6):840-6.

88. Nasiri S, Shafag S, Khorgami Z, Sodagari N, Aminian A, Hedayat A. Does corticosteroid have any beneficial effect on voice change after thyroidectomy? Am Surg. 2013 Dec;79(12):1258-62.
89. Cheng SP, Liu TP, Yang PS, Lee KS, Liu CL. Effect of perioperative dexamethasone on subjective voice quality after thyroidectomy: a meta-analysis and systematic review. Langenbecks Arch Surg. 2015 Dec;400(8):929-36.

90. Kim JS, Kwon SH, Lee SE, Lee EJ, Lee MH. Effect of single-dose intravenous dexamethasone on subjective voice quality after thyroidectomy: a meta-analysis. Medicine (Baltimore). 2018 Sep;97(36): e11832.

91. Noel JE, Kligerman MP, Megwalu UC. Intraoperative corticosteroids for voice outcomes among patients undergoing thyroidectomy: a systematic review and meta-analysis. Otolaryngol Head Neck Surg. 2018 Nov;159(5):811-6.

92. Roy N, Smith ME, Dromey C, Redd J, Neff S, Grennan D. Exploring the phonatory effects of external superior laryngeal nerve paralysis: an in vivo model. Laryngoscope. 2009 Apr;119(4):816-26.

93. Cernea CR, Ferraz AR, Nishio S, Dutra A Jr, Hojaij FC, dos Santos LR. Surgical anatomy of the external branch of the superior laryngeal nerve. Head Neck. 1992 Sep-Oct;14(5):380-3.

94. Bliss RD, Gauger PG, Delbridge LW. Surgeon's approach to the thyroid gland: surgical anatomy and the importance of technique. World J Surg. 2000 Aug;24(8):891-7.

95. Garas G, Okabayashi K,Ashrafian H, Shetty K, Palazzo F, Tolley N, et al. Which hemostatic device in thyroid surgery? A network metaanalysis of surgical technologies. Thyroid. 2013 Sep;23(9):1138-50.

96. Aytac B, Karamercan A. Recurrent laryngeal nerve injury and preservation in thyroidectomy. Saudi Med J. 2005 Nov;26(11):1746-9.

97. Rathi PK, Shaikh AR, Shaikh GA. Identification of recurrent laryngeal nerve during thyroidectomy decreases the risk of nerve injury. Pak J Med Sci. 2010;26(1):148-51.

98. Steurer M, Passler C, Denk DM, Schneider B, Niederle B, Bigenzahn W. Advantages of recurrent laryngeal nerve identification in thyroidectomy and parathyroidectomy and the importance of preoperative and postoperative laryngoscopic examination in more than 1000 nerves at risk. Laryngoscope. 2002 Jan;112(1):124-33.

99. Sturniolo G, D'Alia C, Tonante A, Gagliano E, Taranto F, Lo Schiavo MG. The recurrent laryngeal nerve related to thyroid surgery. Am J Surg. 1999 Jun;177(6):485-8.

100. Shao T, Qiu W, Yang W. Anatomical variations of the recurrent laryngeal nerve in Chinese patients: a prospective study of 2,404 patients. Sci Rep. 2016 May;6:25475.

101. Delbridge L, Reeve TS, Khadra M, Poole AG. Total thyroidectomy: the technique of capsular dissection. Aust N Z J Surg. 1992 Feb; 62(2):96-9.

102. Pelizzo MR, Toniato A, Gemo G. Zuckerkandl's tuberculum: an arrow pointing to the recurrent laryngeal nerve (constant anatomical landmark). J Am Coll Surg. 1998 Sep;187(3):333-6.

103. Mao XC, Chen C, Wang KJ. Efficacy and safety of LigaSureTM small jaw instrument in thyroidectomy: a 1-year prospective observational study. Eur Arch Otorhinolaryngol. 2018 May;275(5):125763.

104. Zhang L, Li N, Yang X, Chen J.A meta-analysis comparing the outcomes of LigaSure Small Jaw versus clamp-and-tie technique or Harmonic Focus Scalpel in thyroidectomy. Medicine (Baltimore). 2017 Mar;96(11):e6141.

105. Bhargav PR,AmarV. Operative technique of endoscopic thyroidectomy: a narration of general principles. Indian J Surg. 2013 Jun; 75(3):216-9.

106. Chang E, Kim HY, Koh YW, Chung WY. Overview of robotic thyroidectomy. Gland Surg. 2017 Jun;6(3):218-28.

107. Bai B, Chen W. Protective effects of intraoperative nerve monitoring (IONM) for recurrent laryngeal nerve injury in thyroidectomy: meta-analysis. Sci Rep. 2018 May;8(1):7761.

108. Cirocchi R, Arezzo A, D’Andrea V, Abraha I, Popivanov GI, Avenia $\mathrm{N}$, et al. Intraoperative neuromonitoring versus visual nerve identi- 
fication for prevention of recurrent laryngeal nerve injury in adults undergoing thyroid surgery. Cochrane Database Syst Rev. 2019 Jan;1(1):CD012483.

109. Higgins TS, Gupta R, Ketcham AS, Sataloff RT, Wadsworth JT, Sinacori JT. Recurrent laryngeal nerve monitoring versus identification alone on post-thyroidectomy true vocal fold palsy: a meta-analysis. Laryngoscope. 2011 May;121(5):1009-17.

110. Lombardi CP, Carnassale G, Damiani G,Acampora A, Raffaelli M, De Crea C, et al. "The final countdown": is intraoperative, intermittent neuromonitoring really useful in preventing permanent nerve palsy? Evidence from a meta-analysis. Surgery. 2016 Dec; 160(6):1693-706.

111. Malik R, Linos D. Intraoperative neuromonitoring in thyroid surgery: a systematic review.World J Surg. 2016 Aug;40(8):2051-8.

112. Rulli F, Ambrogi V, Dionigi G, Amirhassankhani S, Mineo TC, Ottaviani $\mathrm{F}$, et al. Meta-analysis of recurrent laryngeal nerve injury in thyroid surgery with or without intraoperative nerve monitoring. Acta Otorhinolaryngol Ital. 2014 Aug;34(4):223-9.

113. Sanabria A, Ramirez A, Kowalski LP, Silver CE, Shaha AR, Owen RP, et al. Neuromonitoring in thyroidectomy: a meta-analysis of effectiveness from randomized controlled trials. Eur Arch Otorhinolaryngol. 2013 Aug;270(8):2175-89.

114. Sun W, Liu J, Zhang H, Zhang P, Wang Z, Dong W, et al. A metaanalysis of intraoperative neuromonitoring of recurrent laryngeal nerve palsy during thyroid reoperations. Clin Endocrinol (Oxf). 2017 Nov;87(5):572-80.

115. Yang S, Zhou L, Lu Z, Ma B, Ji Q, Wang Y. Systematic review with meta-analysis of intraoperative neuromonitoring during thyroidectomy. Int J Surg. 2017 Mar;39:104-13.

116. Zheng S, Xu Z, Wei Y, Zeng M, He J. Effect of intraoperative neuromonitoring on recurrent laryngeal nerve palsy rates after thyroid surgery: a meta-analysis. J Formos Med Assoc. 2013 Aug;112(8): 463-72.

117. Dralle H, Sekulla C, Haerting J, Timmermann W, Neumann HJ, Kruse E, et al. Risk factors of paralysis and functional outcome after recurrent laryngeal nerve monitoring in thyroid surgery. Surgery. 2004 Dec;136(6):1310-22.

118. Wong KP, Mak KL, Wong CK, Lang BH. Systematic review and meta-analysis on intra-operative neuro-monitoring in high-risk thyroidectomy. Int J Surg. 2017 Feb;38:21-30.

119. Lorenz RR, Esclamado RM, Teker AM, Strome M, Scharpf J, Hicks $\mathrm{D}$, et al. Ansa cervicalis-to-recurrent laryngeal nerve anastomosis for unilateral vocal fold paralysis: experience of a single institution. Ann Otol Rhinol Laryngol. 2008 Jan;117(1):40-5.

120. Miyauchi A, Inoue H,Tomoda C, Fukushima M, Kihara M, Higashiyama T, et al. Improvement in phonation after reconstruction of the recurrent laryngeal nerve in patients with thyroid cancer invading the nerve. Surgery. 2009 Dec;146(6):1056-62.

121. Miyauchi A, Matsusaka K, Kihara M, Matsuzuka F, Hirai K, Yokozawa T, et al.The role of ansa-to-recurrent-laryngeal nerve anastomosis in operations for thyroid cancer. Eur J Surg. 1998 Dec;164(12): 927-33.

122. Su WF, Hsu YD, Chen HC, Sheng H. Laryngeal reinnervation by ansa cervicalis nerve implantation for unilateral vocal cord paralysis in humans. JAm Coll Surg. 2007 Jan;204(1):64-72.

123. Zheng H, Li Z, Zhou S, Cuan Y, Wen W. Update: laryngeal reinnervation for unilateral vocal cord paralysis with the ansa cervicalis. Laryngoscope. 1996 Dec;106(12 Pt 1):1522-7.

124. Lee SW, Park KN, Oh SK, Jung CH, Mok JO, Kim CH. Long-term efficacy of primary intraoperative recurrent laryngeal nerve reinnervation in the management of thyroidectomy-related unilateral vocal fold paralysis. Acta Otolaryngol. 2014 Nov;134(11):1179-84.

125. Paniello RC, Edgar JD, Kallogjeri D, Piccirillo JF. Medialization versus reinnervation for unilateral vocal fold paralysis: a multicenter randomized clinical trial. Laryngoscope. 2011 Oct;121(10):2172-9.

126. Iwaki S, Maeda T, Saito M, Otsuki N,Takahashi M, Wakui E, et al. Role of immediate recurrent laryngeal nerve reconstruction in surgery for thyroid cancers with fixed vocal cords. Head Neck. 2017 Mar;39(3):427-31.

127. Lee SW, Park KN. A long-term comparative prospective study between reinnervation and injection laryngoplasty. Laryngoscope. 2018 Aug;128(8):1893-7.

128. Isseroff TF, Pitman MJ. Optimal management of acute recurrent laryngeal nerve injury during thyroidectomy. Curr Otorhinolaryngol Rep. 2013 Sep;1:163-70.

129. Crumley RL. Laryngeal synkinesis revisited. Ann Otol Rhinol Laryngol. 2000 Apr;109(4):365-71.

130. Lee SW. Management of post-throidectomy voice problems: surgeon's perspectives. Korean J Otorhinolaryngol-Head Neck Surg. 2016 Jan;59(1):1-8.

131. Isshiki N, Okamura $\mathrm{H}$, Ishikawa T. Thyroplasty type I (lateral compression) for dysphonia due to vocal cord paralysis or atrophy. Acta Otolaryngol. 1975 Nov-Dec;80(5-6):465-73.

132. McCulloch TM, Hoffman HT, Andrews BT, Karnell MP. Arytenoid adduction combined with Gore-Tex medialization thyroplasty. Laryngoscope. 2000 Aug;110(8):1306-11.

133. Aynehchi BB, McCoul ED, Sundaram K. Systematic review of laryngeal reinnervation techniques. Otolaryngol Head Neck Surg. 2010 Dec;143(6):749-59.

134. Paniello RC. Laryngeal reinnervation. Otolaryngol Clin North Am. 2004 Feb;37(1):161-81.

135. Hong JW, Roh TS, Yoo HS, Hong HJ, Choi HS, Chang HS, et al. Outcome with immediate direct anastomosis of recurrent laryngeal nerves injured during thyroidectomy. Laryngoscope. 2014 Jun; 124(6):1402-8.

136. Sanuki T, Yumoto E, Minoda R, Kodama N. The role of immediate recurrent laryngeal nerve reconstruction for thyroid cancer surgery. J Oncol. 2010;2010:846235.

137. Wang W, Chen D, Chen S, Li D, Li M, Xia S, et al. Laryngeal reinnervation using ansa cervicalis for thyroid surgery-related unilateral vocal fold paralysis: a long-term outcome analysis of 237 cases. PLoS One. 2011Apr;6(4):e19128.

138. Eadie TL, Kapsner M, Rosenzweig J, Waugh P, Hillel A, Merati A. The role of experience on judgments of dysphonia. J Voice. 2010 Sep;24(5):564-73.

139. Lacoste L, Karayan J, Lehuede MS, Thomas D, Goudou-Sinha M, Ingrand $\mathrm{P}$, et al. A comparison of direct, indirect, and fiberoptic laryngoscopy to evaluate vocal cord paralysis after thyroid surgery. Thyroid. 1996 Feb;6(1):17-21.

140. Dionigi G, Boni L, Rovera F, Rausei S, Castelnuovo P, Dionigi R. Postoperative laryngoscopy in thyroid surgery: proper timing to detect recurrent laryngeal nerve injury. Langenbecks Arch Surg. 2010 Apr;395(4):327-31.

141. Bures C, Bobak-Wieser R, Koppitsch C, KlatteT, Zielinski V, Freissmuth $\mathrm{M}$, et al. Late-onset palsy of the recurrent laryngeal nerve after thyroid surgery. Br J Surg. 2014 Nov;101(12):1556-9.

142. Friedman AD, Burns JA, Heaton JT, Zeitels SM. Early versus late injection medialization for unilateral vocal cord paralysis. Laryngoscope. 2010 Oct;120(10):2042-6.

143. Yung KC, Likhterov I, Courey MS. Effect of temporary vocal fold injection medialization on the rate of permanent medialization laryngoplasty in unilateral vocal fold paralysis patients. Laryngoscope. 2011 Oct;121(10):2191-4.

144. Stojadinovic A, Shaha AR, Orlikoff RF, Nissan A, Kornak MF, Singh $\mathrm{B}$, et al. Prospective functional voice assessment in patients undergoing thyroid surgery. Ann Surg. 2002 Dec;236(6):823-32.

145. Page C, Zaatar R, Biet A, Strunski V. Subjective voice assessment after thyroid surgery: a prospective study of 395 patients. Indian J 
Med Sci. 2007 Aug;61(8):448-54.

146. Boone DR, McFarlane SC, Von Berg SL, Zraick RI. The voice and voice therapy. 10th ed. Hoboken: Pearson Education; 2019.

147. Tedla M, Chakrabarti S, Suchankova M, Weickert MO. Voice outcomes after thyroidectomy without superior and recurrent laryngeal nerve injury: VoiSS questionnaire and GRBAS tool assessment. Eur Arch Otorhinolaryngol. 2016 Dec;273(12):4543-7.

148. Sung E, Lee JC, Song CM, Ji Y, Tae K. Long-term serial follow-up of voice outcome after thyroidectomy. Otolaryngol Head Neck Surg. 2016 Sep;155(S1):P171.

149. Debruyne F, Ostyn F, Delaere P,Wellens W, DecosterW.Temporary voice changes after uncomplicated thyroidectomy. Acta Otorhinolaryngol Belg. 1997;51(3):137-40.

150. Shonka DC Jr, Terris DJ. The American Thyroid Association guidelines on voice assessment: have we done enough? JAMA Otolaryngol Head Neck Surg. 2016 Feb;142(2):115-6.

151. Sorensen JR, Dossing H, Bonnema SJ, Hegedus L, Printz T, Godballe $\mathrm{C}$. Voice changes after thyroidectomy impacts quality of life. Otolaryngol Head Neck Surg. 2017 Sep;157(S1):P171.

152. Lee SJ, Lim SE, Choi HS. Responsiveness of the Korean version of the Voice Activity and Participation Profile (K-VAPP) after surgical intervention. Commun Sci Disord. 2017;22(2):379-90.

153. Lee SJ, Choi HS, Kim H, Byeon HK, Lim SE, Yang MK, et al. Korean version of the Voice Activity and Participation Profile (K-VAPP): a validation study. Commun Sci Disord. 2016 Dec;21(4):695-708.

154. Lang BH,Wong CK, Ma EP.A systematic review and meta-analysis on acoustic voice parameters after uncomplicated thyroidectomy. Laryngoscope. 2016 Feb;126(2):528-37.

155. Minni A, Ruoppolo G, Barbaro M, Di Lorenzo E, Sementilli G, Bononi M. Long-term (12 to 18 months) functional voice assessment to detect voice alterations after thyroidectomy. Eur Rev Med Pharmacol Sci. 2014;18(12):1704-8.

156. Ortega J, Cassinello N, Dorcaratto D, Leopaldi E. Computerized acoustic voice analysis and subjective scaled evaluation of the voice can avoid the need for laryngoscopy after thyroid surgery. Surgery. 2009 Mar;145(3):265-71.

157. Solomon NP, Awan SN, Helou LB, Stojadinovic A. Acoustic analyses of thyroidectomy-related changes in vowel phonation. J Voice. 2012 Nov;26(6):711-20.

158. Iyomasa RM,Tavares EL, Castilho EC, Veloso IL, Tagliarini JV, Martins RH.Videolaryngoscopy, vocal symptoms assessment, and voice acoustic features in patients undergoing thyroid surgery. Int Arch Otorhinolaryngol. 2014;18:a2450.

159. Dixon H,Amin N, Roplekar R, Lindisfarne E, Gibbins N, Harries M. Assessment of voice in thyroidectomy patients: an audit cycle. Otorhinolaryngologist. 2013;6(2):122-4.

160. Kletzien H, Macdonald CL, Orne J, Francis DO, Leverson G, Wendt E, et al. Comparison between patient-perceived voice changes and quantitative voice measures in the first postoperative year after thyroidectomy: a secondary analysis of a randomized clinical trial. JAMA Otolaryngol Head Neck Surg. 2018 Nov;144(11):9951003.

161. Lee SJ, Lim SE, Choi HS. A comparison of cepstral and spectral measures according to measurement position in a reading passage. Commun Sci Disord. 2017 Dec;22(4):818-26.

162. Lee SJ, Pyo HY, Choi HS. Normative data of cepstral and spectral measures in Korean adults using vowel phonation and passage reading tasks. Commun Sci Disord. 2018 Mar;23(1):208-17.

163. Yu M, Choi SH, Choi CH, Choi B. Predicting normal and pathological voice using a cepstral based acoustic index in sustained vowels versus connected speech. Commun Sci Disord. 2018 Dec;23(4): 1055-64.

164. Desuter G, Dedry M, Schaar B, van Lith-Bijl J, van Benthem PP, Sjogren EV. Voice outcome indicators for unilateral vocal fold pa- ralysis surgery: a review of the literature. Eur Arch Otorhinolaryngol. 2018 Feb;275(2):459-68.

165. Lo CY, Kwok KF, Yuen PW. A prospective evaluation of recurrent laryngeal nerve paralysis during thyroidectomy. Arch Surg. 2000 Feb;135(2):204-7.

166. Affleck BD, Swartz K, Brennan J. Surgical considerations and controversies in thyroid and parathyroid surgery. Otolaryngol Clin North Am. 2003 Feb;36(1):159-87.

167. Lee DH, Lee SY, Lee M, Seok J, Park SJ, JinYJ, et al. Natural course of unilateral vocal fold paralysis and optimal timing of permanent treatment. JAMA Otolaryngol Head Neck Surg. 2020 Jan;146(1): 30-5.

168. Husain S, Sadoughi B, Mor N, Levin AM, Sulica L. Time course of recovery of idiopathic vocal fold paralysis. Laryngoscope. 2018 Jan;128(1):148-52.

169. MauT, Pan HM, Childs LF. The natural history of recoverable vocal fold paralysis: implications for kinetics of reinnervation. Laryngoscope. 2017 Nov;127(11):2585-90.

170. Sulica L. The natural history of idiopathic unilateral vocal fold paralysis: evidence and problems. Laryngoscope. 2008 Jul;118(7): 1303-7.

171. Vila PM, Bhatt NK, Paniello RC. Early-injection laryngoplasty may lower risk of thyroplasty: a systematic review and meta-analysis. Laryngoscope. 2018 Apr;128(4):935-40.

172. Lee SW, Kim JW, Chung CH, Mok JO, Shim SS, Koh YW, et al. Utility of injection laryngoplasty in the management of post-thyroidectomy vocal cord paralysis. Thyroid. 2010 May;20(5):513-7.

173. Halderman AA, Bryson PC, Benninger MS, Chota R. Safety and length of benefit of restylane for office-based injection medialization-a retrospective review of one institution's experience. J Voice. 2014 Sep;28(5):631-5.

174. Silva Merea V, Husain S, Sulica L. Medialization laryngoplasty after injection augmentation. JVoice. 2018 Mar;32(2):249-55.

175. Vinson KN, Zraick RI, Ragland FJ. Injection versus medialization laryngoplasty for the treatment of unilateral vocal fold paralysis: follow-up at six months. Laryngoscope. 2010 Sep;120(9):1802-7.

176. Morgan JE, Zraick RI, Griffin AW, Bowen TL, Johnson FL. Injection versus medialization laryngoplasty for the treatment of unilateral vocal fold paralysis. Laryngoscope. 2007 Nov;117(11):2068-74.

177. Shen T, Damrose EJ, Morzaria S. A meta-analysis of voice outcome comparing calcium hydroxylapatite injection laryngoplasty to silicone thyroplasty. Otolaryngol Head Neck Surg. 2013 Feb;148(2): 197-208.

178. Fang TJ, Pei YC, Li HY, Wong AM, Chiang HC. Glottal gap as an early predictor for permanent laryngoplasty in unilateral vocal fold paralysis. Laryngoscope. 2014 Sep;124(9):2125-30.

179. Nouwen J, Hans S, De Mones E, Brasnu D, Crevier-Buchman L, Laccourreye O. Thyroplasty type I without arytenoid adduction in patients with unilateral laryngeal nerve paralysis: the montgomery implant versus the Gore-Tex implant. Acta Otolaryngol. 2004 Aug; 124(6):732-8.

180. Elnashar I, El-Anwar M, Amer H, Quriba A. Voice outcome after Gore-Tex medialization thyroplasty. Int Arch Otorhinolaryngol. 2015 Jul;19(3):248-54.

181. Storck C, Brockmann M, Schnellmann E, Stoeckli SJ, Schmid S. Functional outcome of vocal fold medialization thyroplasty with a hydroxyapatite implant. Laryngoscope. 2007 Jun;117(6):1118-22.

182. Young VN, Zullo TG, Rosen CA. Analysis of laryngeal framework surgery: 10-year follow-up to a national survey. Laryngoscope. 2010 Aug;120(8):1602-8.

183. Hess M, Schroeder D, Puschel K. Sling arytenoid adduction. Eur Arch Otorhinolaryngol. 2011 Jul;268(7):1023-8.

184. Chester MW, Stewart MG. Arytenoid adduction combined with medialization thyroplasty: an evidence-based review. Otolaryngol 
Head Neck Surg. 2003 Oct;129(4):305-10.

185. Mortensen M, Carroll L, Woo P.Arytenoid adduction with medialization laryngoplasty versus injection or medialization laryngoplasty: the role of the arytenoidopexy. Laryngoscope. 2009 Apr;119(4): 827-31.

186. Chang J, Schneider SL, Curtis J, Langenstein J, Courey MS, Yung KC. Outcomes of medialization laryngoplasty with and without arytenoid adduction. Laryngoscope. 2017 Nov;127(11):2591-5.

187. Li AJ, Johns MM, Jackson-Menaldi C, Dailey S, Heman-Ackah Y, Merati A, et al. Glottic closure patterns: type I thyroplasty versus type I thyroplasty with arytenoid adduction. J Voice. 2011 May; 25(3):259-64

188. Feehery JM, Pribitkin EA, Heffelfinger RN, Lacombe VG, Lee D, Lowry LD, et al. The evolving etiology of bilateral vocal fold immobility. JVoice. 2003 Mar;17(1):76-81.

189. Rosenthal LH, Benninger MS, Deeb RH. Vocal fold immobility: a longitudinal analysis of etiology over 20 years. Laryngoscope. 2007 Oct;117(10):1864-70.

190. Pinto JA, Godoy LB, Marquis VW, Sonego TB, Leal Cde F. Bilateral vocal fold immobility: diagnosis and treatment. Braz J Otorhinolaryngol. 2011 Sep-Oct;77(5):594-9.

191. Bogdasarian RS, Olson NR. Posterior glottic laryngeal stenosis. Otolaryngol Head Neck Surg (1979). 1980 Nov-Dec;88(6):765-72.

192. Andrade Filho PA, Rosen CA. Bilateral vocal fold paralysis: an unusual treatment with botulinum toxin. J Voice. 2004 Jun;18(2): 254-5.

193. Nawka T, Sittel C,Arens C, Lang-Roth R, Wittekindt C, Hagen R, et al.Voice and respiratory outcomes after permanent transoral surgery of bilateral vocal fold paralysis. Laryngoscope. 2015 Dec;125(12): 2749-55.

194. Li Y, Garrett G, Zealear D. Current treatment options for bilateral vocal fold paralysis: a state-of-the-art review. Clin Exp Otorhinolaryngol. 2017 Sep;10(3):203-12.

195. Su WF, Liu SC, Tang WS, Yang MC, Lin YY, Huang TT. Suture lateralization in patients with bilateral vocal fold paralysis. JVoice. 2014 Sep;28(5):644-51.

196. Ozdemir S, Tuncer U,Tarkan O, Kara K, Surmelioglu O. Carbon dioxide laser endoscopic posterior cordotomy technique for bilateral abductor vocal cord paralysis: a 15-year experience. JAMA Otolaryngol Head Neck Surg. 2013 Apr;139(4):401-4.

197. Szakacs L, Sztano B, Matievics V, Bere Z, Bach A, Castellanos PF, et al. A comparison between transoral glottis-widening techniques for bilateral vocal fold immobility. Laryngoscope. 2015 Nov;125(11): 2522-9.

198. Yilmaz T. Endoscopic partial arytenoidectomy for bilateral vocal fold paralysis: medially based mucosal flap technique. JVoice. 2019 Sep;33(5):751-8.

199. Rodriguez-Torres J, Lopez-Lopez L, Cabrera-Martos I, Torres-Sanchez I, Ortiz-Rubio A,Valenza MC. Musculoskeletal neck disorders in thyroid cancer patients after thyroidectomy. Eur J Cancer Care (Engl). 2019 Jul;28(4):e13053.

200. Lang BH, Ng SH, Wong KP. Pain and surgical outcomes with and without neck extension in standard open thyroidectomy: a prospective randomized trial. Head Neck. 2015 Mar;37(3):407-12.

201. Takamura Y, Miyauchi A, Tomoda C, Uruno T, Ito Y, Miya A, et al. Stretching exercises to reduce symptoms of postoperative neck discomfort after thyroid surgery: prospective randomized study. World J Surg. 2005 Jun;29(6):775-9.
202. Lombardi CP, Raffaelli M, D’Alatri L, Marchese MR, Rigante M, Paludetti G, et al. Voice and swallowing changes after thyroidectomy in patients without inferior laryngeal nerve injuries. Surgery. 2006 Dec;140(6):1026-32.

203. Lombardi CP, Raffaelli M, De Crea C, D'Alatri L, Maccora D, Marchese MR, et al. Long-term outcome of functional post-thyroidectomy voice and swallowing symptoms. Surgery. 2009 Dec;146(6): 1174-81.

204. Lee JS, Kim JP, Ryu JS, Woo SH. Effect of wound massage on neck discomfort and voice changes after thyroidectomy. Surgery. 2018 Nov;164(5):965-71.

205. Ayhan H, Tastan S, Iyigun E, Ozturk E, Yildiz R, Gorgulu S. The effectiveness of neck stretching exercises following total thyroidectomy on reducing neck pain and disability: a randomized controlled trial.Worldviews Evid Based Nurs. 2016 Jun;13(3):224-31.

206. Kim K, Gu MO, Jung JH, Hahm JR, Kim SK, Kim JH, et al. Efficacy of a home-based exercise program after thyroidectomy for thyroid cancer patients. Thyroid. 2018 Feb;28(2):236-45.

207. Genc A, Celik SU, Genc V, Gokmen D, Tur BS. The effects of cervical kinesiotaping on neck pain, range of motion, and disability in patients following thyroidectomy: a randomized, double-blind, sham-controlled clinical trial. Turk J Med Sci. 2019 Aug;49(4):118591.

208. Stachler RJ, Francis DO, Schwartz SR, Damask CC, Digoy GP, Krouse HJ, et al. Clinical practice guideline: hoarseness (dysphonia) (update). Otolaryngol Head Neck Surg. 2018 Mar;158(1_ suppl):S1-42.

209. Yu WV,Wu CW. Speech therapy after thyroidectomy. Gland Surg. 2017 Oct;6(5):501-9.

210. Guzman M, Castro C, Madrid S, Olavarria C, Leiva M, Munoz D, et al. Air pressure and contact quotient measures during different semioccluded postures in subjects with different voice conditions. J Voice. 2016 Nov;30(6):759.e1-759.e10.

211. Heuer RJ, Sataloff RT, Emerich K, Rulnick R, Baroody M, Spiegel JR, et al. Unilateral recurrent laryngeal nerve paralysis: the importance of "preoperative" voice therapy. J Voice. 1997 Mar;11(1): 88-94.

212. Isshiki N. Mechanical and dynamic aspects of voice production as related to voice therapy and phonosurgery. Otolaryngol Head Neck Surg. 2000 Jun;122(6):782-93.

213. Schindler A, Bottero A, Capaccio P, Ginocchio D, Adorni F, Ottaviani F. Vocal improvement after voice therapy in unilateral vocal fold paralysis. JVoice. 2008 Jan;22(1):113-8.

214. Mattioli F, Menichetti M, Bergamini G, Molteni G, Alberici MP, Luppi MP, et al. Results of early versus intermediate or delayed voice therapy in patients with unilateral vocal fold paralysis: our experience in 171 patients. JVoice. 2015 Jul;29(4):455-8.

215. Ptok M, Strack D. Electrical stimulation-supported voice exercises are superior to voice exercise therapy alone in patients with unilateral recurrent laryngeal nerve paresis: results from a prospective, randomized clinical trial. Muscle Nerve. 2008 Aug;38(2):1005-11.

216. Anderson SK, Terris DJ. Complications of endoscopic neck surgery. In: Eisele DW, Smith RV, editors. Complications in head and neck surgery. 2nd ed. Philadelphia (PA): Mosby; 2009. p. 467-75.

217. Nam IC, Bae JS, Chae BJ, Shim MR, Hwang YS, Sun DI. Therapeutic approach to patients with a lower-pitched voice after thyroidectomy.World J Surg. 2013 Aug;37(8):1940-50. 